\title{
Investigation and Research on the Development Level of Primary School Students' Information Literacy in Western China and its Development Strategy
}

\author{
Shu Han ${ }^{1}$, Yushun $\mathrm{Li}^{1}$ \\ ${ }^{1}$ Education Department, Beijing Normal University, Beijing, China \\ Correspondence: Yushun Li, Digital learning and education public service engineering research center of the Ministry \\ of Education, Beijing Normal University, Beijing, China.
}

Received: June 4, $2021 \quad$ Accepted: June 24, $2021 \quad$ Online Published: June 24, 2021

doi:10.11114/jets.v9i6.5271 URL: https://doi.org/10.11114/jets.v9i6.5271

\begin{abstract}
In this study, the current situation of information literacy level of primary school students in western China, mainly in Lanzhou, Gansu Province, was investigated by Means of questionnaire and interview. The survey results show that there is a big gap between urban and rural primary school students' information literacy level, mainly because rural schools do not enjoy good resource allocation. In addition, it is found that there is no significant difference in information literacy level between genders, but there are still some gender stereotypes. On the whole, students' information literacy level is at a medium level, and information technology use behavior is mostly at a low level, while high-level behavior is less. The information literacy of primary school students in western China still needs further development.
\end{abstract}

Keywords: information literacy, urban-rural education gap, gender difference

\section{Introduction}

Information literacy (IL) is an important component of skills in the 21st century(Gut,2011) (Kang, Heo, Jo, Shin, \& Seo,2010), which is also a basic skill that students must possess in the 21 st century. Since the Ministry of Education focused on developing students' information literacy, many researchers have studied and discussed information literacy, including its connotation, model, curriculum practice and measurement and evaluation. In the research of measurement and evaluation, few studies can pay attention to the information literacy level of students in western China, and few studies have carried out large-scale measurement and evaluation of students' information literacy in western China. The study of this problem can help primary schools in western China to understand the gap of students' information literacy among schools. According to this research, we can understand the overall development level of students' information literacy in the western region. It can also provide portable excellent experience and development strategies for schools in western China to improve the information literacy of primary school students. It can provide reference for future research in this field. Therefore, the research questions of this study are as follows:

1) Since the international emphasis on developing students' information literacy, what is the development status of students' information literacy in western China?

2) What are the difficulties and challenges?

3) What are the suggestions or feasible strategies?

\section{Literature Review}

Web 2.0, which is coined by Tim O'Reilly of O'Reilly Media,(O'Reilly,2005) describes the ability to enhance creativity, communications, secure information sharing, collaboration. The essence of Web 2.0 is participation in creating information dynamically.(Dan,2009) Information literacy also includes these abilities. Information literacy refers to knowing when information is needed and the ability to effectively locate, evaluate, and use that needed information.(2005) Vorobel have explored language learners' digital information literacy and online reading practices.(Vorobel, Voorhees, \& Gokcora,2021) Some article shows that information literacy community-of-learners(Wang,2007), inquiry project-based learning (PjBL) has a positive impact of on the development 
of the students' information literacy.(Chu, Tse, \& Chow,2011) Reducing cognitive load is crucial for the acquisition of information-seeking knowledge. Teachers should provide well-structured online tutorials and instructional modules.(Rosman, Mayer, \& Krampen,2016) Some researchers found that attitude(Wen \& Shih,2008) and Gender(Hatlevik, Throndsen, Loi, \& Gudmundsdottir,2018) play important roles in understanding students' computer and information literacy. Some researchers propose a convergent model for information literacy (IL) based on web literacy, in which identifies three dimensions of IL and IT: web environment knowledge, web development knowledge, and research skills.(Mackey \& Ho,2005) Pinto developed a framework named IL-HUMASS which contained 26 items grouped into four categories (information search, assessment, processing and communication /dissemination ) and three self-reporting dimensions (motivation, self-efficacy and favourite source of learning).(Pinto,2010) Huggins certified The ST2L is a sound measure of ICT literacy with using item response theory and test.(Huggins, Ritzhaupt, \& Dawson,2014) In addition, some large-scale research institutions have also conducted research on information literacy evaluation.

In 2010, the United Nations Educational Scientific and Cultural Organization (UNESCO) published Towards Media and Information Literacy Indicators (Moeller, Joseph, Lau, \& Carbo,2010) and pointed out that media and information literacy mainly includes three aspects: access/retrieval of information, evaluation/understanding of information, and utility/creation/exchange of information. In 2011, the British Association of National and University Libraries (SCONUL) published seven pillar models of information literacy(Bent, Stubbings, \& SCONUL,2011), including identifying information needs, researching information needs, planning retrieval strategies, obtaining information, evaluating information, managing knowledge and displaying knowledge. The cycle of this model (as shown in Picture 1) shows that information literacy is not a linear process.

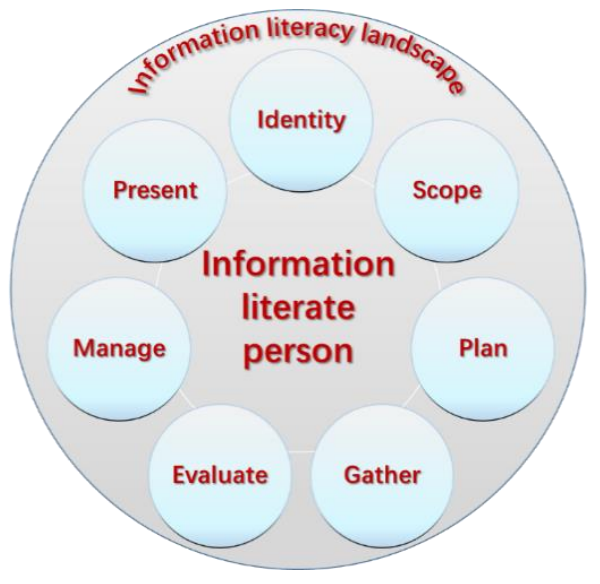

Figure 1. Information literacy model by SCONUL

In 2014, the International Association for Evaluation of Educational Achievement (IEA) released the Framework for Evaluation of Computer and Information Literacy (Gebhardt et al.,2014). The evaluation framework is divided into two parts: collecting and managing information and producing and exchanging information. In 2015, ARCL released the framework for evaluating information literacy in higher education (ACRL,2015), which emphasized the importance of metacognition training. FOO and others constructed five dimensions, including defining information tasks and analyzing information deficiency; Select the information source; Searching and evaluating information; Analyze and use information; Evaluation of information process and results, and widely used in the evaluation of information literacy of middle school students in Singapore (Foo, Majid, \& Chang,2017). 


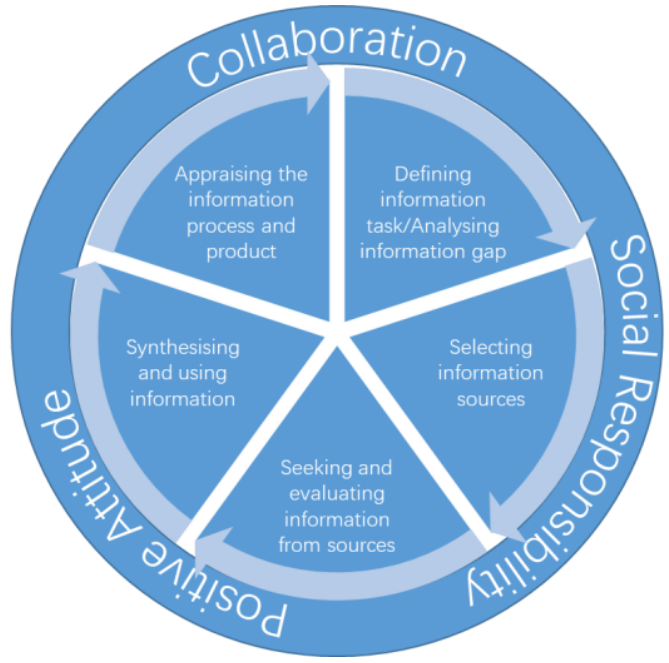

Figure 2. Evaluation of information literacy of middle school students in Singapore by FOO

Educational testing service (ETS) divides ICT quality into seven dimensions: information description, acquisition, management, integration, evaluation, creation and expression (Panel,2002), and develops iSkills test system to evaluate students' ICT quality. Australia NAP-ICT Project (Qingyu \& Yi,2013)has developed a self-adaptive evaluation system, which can randomly assign evaluation mode and management mode. TRAILS: Tool for Real-time Assessment of Information Literacy Skills has been developed by Kent State University in the United States(Schloman \& Gedeon,2016), which is suitable for students from grade three, grade six, grade nine and grade twelve. SAILS project for higher education (Emmett \& Emde,2007) is based on IRT, and adopts adaptive test method to automatically adjust the difficulty of evaluation questions according to students' level, so as to reflect students' information literacy level more truly.

Central China Normal University put forwards an information literacy evaluation index system for primary and secondary school students (Yinghui, Changling, Di, \& Hao,2018). Its dimensions include: information awareness and cognition, information science knowledge, information application and innovation, information morality and law, and also developed an information literacy evaluation tool for middle school students. (Sha, Yinghui, Longyan, \& Liqin,2018)

From the evaluation object, international and domestic organizations pay more attention to the information literacy evaluation of college students in higher education, and the information literacy evaluation of higher education learners is relatively mature. From the evaluation framework of international organizations, information literacy emphasizes not only the use of technical tools, but also the individual critical, reflective and creative abilities of learners.

\section{Methodology}

\subsection{Context}

The whole research process can be divided into two stages. In the early stage, the network-based questionnaire survey is the main research method; In the later period, the interview based on field investigation was taken as the main research method, and the interview process included focus group interview and individualized interview. The subjects of questionnaire survey are primary school students, and the subjects of interview are primary school students and teachers. They all come from ten primary schools in Lanzhou, Gansu Province, which are Qilihe Primary School, Dongjiao Primary School, Lanzhou Experimental Primary School, Ningwozhuang Primary School, Beijing Second Experimental Primary School Lanzhou Branch, Hongshangen Primary School, Northwest Normal University Affiliated Primary School, Wushengyi Primary School, Lvjiaxian Primary School and Houdiwan Primary School. The first three schools are located in cities, the middle four schools are located in towns and villages, and the last three primary schools are located in remote areas.

The research process mainly includes the following eight steps: First, combing the model and framework of core literacy evaluation through literature research, and combining the research of core literacy development evaluation at home and abroad, sorting out feasible questionnaire dimensions. Secondly, design and test the corresponding items for each dimension, analyze the reliability and validity of the questionnaire, and modify or delete the items whose reliability and validity are not up to standard; Fourth, the completed questionnaire will be officially distributed, and then the data will be collected, processed and analyzed; Fifth, sort out an interview outline according to the dimensions of the questionnaire and the results of data analysis; Sixth, conduct field interviews and research, and divide the 
interviewers into two groups, one in urban schools and the other in rural schools, and record the interview process; Seventh, transcribe the audio materials and arrange the transcribed texts; Finally, combined with the data analysis results and interview texts, based on the situation of ten schools, the development of information literacy of primary school students in western China is obtained, some excellent experiences and challenges are extracted, and feasible strategies are put forward.

\subsection{Questionnaire Survey}

\subsubsection{Participants}

Considering the validity of the questionnaire survey, the subjects of the questionnaire survey are the senior primary school students, that is, the fourth, fifth and sixth grade students. The sample includes $51.52 \%$ boys and $48.48 \%$ girls, and the gender distribution ratio is relatively balanced. The number of students in grade four, grade five and grade six is close; The Han population occupies the vast majority; Students in urban schools account for the vast majority. Descriptive statistics of samples are shown in Table 1.

Table 1. Descriptive statistics of samples

\begin{tabular}{ccc}
\hline $\begin{array}{c}\text { Demographic } \\
\text { characteristics }\end{array}$ & category & percentage \\
\hline \multirow{2}{*}{ Gender } & male & $51.52 \%$ \\
& female & $48.48 \%$ \\
Ethnic group & Han & $93.33 \%$ \\
& Ethnic minorities & $6.67 \%$ \\
Regional level & city & $93.15 \%$ \\
of the school & County, township and & $6.85 \%$ \\
& village & $33.9 \%$ \\
Grade & Grade 4 & $35.8 \%$ \\
& Grade 5 & $30.3 \%$ \\
\hline
\end{tabular}

\subsubsection{Survey Instruments}

Considering the number of items and the region where the questionnaire is applied, this study continues to use access/retrieve information (ARI), evaluation/understanding information (EUI), utility/creating/exchanging information (UCEI), and adding two new dimensions: cognition and expression of information technology course(CEITC) and gender differences in the utility of information technology(GDUIT). The questionnaire is in the form of 5-point Likert, with values ranging from 1 to 5 , which Means "very inconsistent" 1 point, "inconsistent" 2 points, "neutral" 3 points, "consistent" 4 points and "very consistent" 5 points respectively. The questionnaire factors and some items are shown in Table 2. 
Table 2. The questionnaire of students' information literacy used in this study

\begin{tabular}{|c|c|c|}
\hline Factor Name & Factor Meaning & Examples of items \\
\hline $\begin{array}{l}\text { Access/Retrieve } \\
\text { information(ARI) }\end{array}$ & $\begin{array}{l}\text { Recognizing the demand } \\
\text { for, being able to search } \\
\text { for, being able to access } \\
\text { and retrieve information } \\
\text { and media content }\end{array}$ & $\begin{array}{l}\text { 1. I know how to find useful information through the network. } \\
\text { 2. I will use computers to collect information from different } \\
\text { sources. } \\
\text { 3. I will look for useful information to help my study through } \\
\text { the Internet. }\end{array}$ \\
\hline $\begin{array}{l}\text { Evaluate/Understand } \\
\text { information(EUI) }\end{array}$ & $\begin{array}{l}\text { Understanding, } \\
\text { assessment and } \\
\text { evaluation of } \\
\text { information and media }\end{array}$ & $\begin{array}{l}\text { 1. I judge the authenticity of network information by } \\
\text { comparing various information sources. } \\
\text { 2. I know which websites and information are reliable. } \\
\text { 3. I will use computers to integrate information from different } \\
\text { sources. }\end{array}$ \\
\hline $\begin{array}{l}\text { Use/Create/Exchange } \\
\text { information(UCEI) }\end{array}$ & $\begin{array}{l}\text { Creation, utilization and } \\
\text { monitoring } \\
\text { information and media } \\
\text { content }\end{array}$ & $\begin{array}{l}\text { 1. I can express my understanding of knowledge by making } \\
\text { electronic documents (such as PPT, Word, etc.). } \\
\text { 2. I actively communicate with my classmates online to learn } \\
\text { new knowledge. } \\
\text { 3. I use the computer to record all kinds of thoughts during my } \\
\text { study. }\end{array}$ \\
\hline $\begin{array}{l}\text { Cognition and } \\
\text { expression of } \\
\text { information technology } \\
\text { course(CEITC) }\end{array}$ & $\begin{array}{l}\text { Study, application and } \\
\text { attitude } r \text { towards } \\
\text { information } \\
\text { courses }\end{array}$ & $\begin{array}{l}\text { 1. Learning information technology is very helpful to my daily } \\
\text { life. } \\
\text { 2. I think it is very important to study information technology. } \\
\text { 3. My computer knowledge and skills mainly come from } \\
\text { information technology classroom learning. }\end{array}$ \\
\hline $\begin{array}{l}\text { Gender differences in } \\
\text { the utility of } \\
\text { information } \\
\text { technology(GDUIT) }\end{array}$ & $\begin{array}{l}\text { Gender differences in } \\
\text { information technology } \\
\text { use }\end{array}$ & $\begin{array}{l}\text { 1. In information technology class, boys learn faster than girls. } \\
\text { 2. I like playing video games in my spare time. } \\
\text { 3. I feel that boys have better hands-on ability than girls. }\end{array}$ \\
\hline
\end{tabular}

3.3 Interview-based Field Survey

\subsubsection{Participants}

A total of 62 students and 67 teachers were interviewed. Students interviewed are concentrated in the fourth, fifth and sixth grades, and very few students are in the second or third grade. These teachers come from various subjects and grades in primary school.

\subsubsection{Survey Instruments}

Semi-structured interview is adopted, and the interview questions revolve around the following interview framework, but are not limited to these questions. 
Table 3. The interview outline of students' information literacy

\begin{tabular}{l} 
Interview outline for students \\
\hline 1. Do you like information technology classes? Talk about your experience. \\
2. Do you use the following techniques in class? Multimedia, interactive whiteboard, tablet \\
computer, online network, etc. How is your learning experience? \\
3. Will the teacher recommend some learning apps and websites to you? What are the learning \\
apps you often use, and what are their functions? \\
4. Will the teacher assign homework for you to finish with your mobile phone or Pad? Besides \\
doing homework, what will the teacher ask you to do with your mobile phone or Pad? Do your \\
parents object? \\
5. Have you done any experiments in a virtual laboratory? How does it feel? \\
6. Do you take extra-curricular tutoring classes and what do you study? You can talk about your \\
feelings in this respect (such as whether you like it or not, whether you chose it or reported it by \\
your parents). \\
7. Besides playing games with Pad or mobile phone, what is your favorite thing to do with Pad or \\
mobile phone? \\
8. Have you ever participated in robot competitions, maker competitions and other activities at \\
school or off campus? \\
9. Have you tried to solve problems in your study or life with the help of the network and related \\
equipment (for example, searching for learning materials online)?
\end{tabular}

\subsection{Data Collection}

The questionnaire has been published on the Internet since March 15, 2021, and as of March 29, 2021, a total of 3,979 questionnaires have been collected, among which 3,900 valid questionnaires remain. The field interview ended from the afternoon of April 6, 2021 to noon of April 9, 2021, and the interview process was recorded by electronic devices such as mobile phones and voice recorders.

\section{Data Analysis and Results}

Using valid samples to test in SPSS 20.0, the reliability of the questionnaire is 0.894 , and the overall reliability of the questionnaire is good. In addition, the reliability of each dimension is reported as follows: ARI's $\alpha=0.906>0.9$, EUI's $\alpha=0.920>0.9$, UCEI's $\alpha=0.899>0.8$, CEITC's $\alpha=0.872>0.8$, GDUIT's $\alpha=0.928>0.9$. The reliability coefficient of each dimension is greater than 0.8 . Therefore, the reliability of each dimension is good. The questionnaire has good internal consistency. The reliability of each dimension and the overall reliability of the questionnaire are shown in Table 4.

Table 4. Reliability, Mean, variance, standard deviation and item number of the questionnaire (keep three decimal places)

\begin{tabular}{lcccccc}
\hline Statistical item & ARI & EUI & UCEI & CEITC & GDUIT & General questionnaire \\
\hline Cronbach $\alpha$ & 0.906 & 0.920 & 0.899 & 0.927 & 0.921 & 0.918 \\
MEAN & 4.006 & 3.515 & 3.398 & 3.990 & 3.020 & 3.788 \\
SD & 0.032 & 0.008 & 0.017 & 0.008 & 0.021 & 0.285 \\
Number of terms & 4 & 4 & 4 & 7 & 5 & 24 \\
\hline
\end{tabular}

The validity of the questionnaire was analyzed and individual items were adjusted. Bartlett spherical test showed that $\mathrm{p}=0.000$ and $\mathrm{KMO}$ value was $0.948(>0.9)$. Therefore, the items of this questionnaire are very suitable for validity analysis and the questionnaire has good structural validity. Using principal component analysis to extract factors combined with maximum variance rotation technique, the number of extracted components is consistent with the preset number of factors.

Table 5. KMO and Bartlett's Test

\begin{tabular}{lrrr}
\hline KMO & \multicolumn{3}{c}{ Bartlett's Test } \\
\hline & Chi. & df & Sig. \\
0.948 & 27397.516 & 276 & 0.000 \\
\hline
\end{tabular}


Table 6. Rotated component matrix

\begin{tabular}{lrrrrc}
\hline & \multicolumn{5}{c}{ Components } \\
& 1 & 2 & 3 & \multicolumn{1}{c}{4} & 5 \\
\hline CEITC_1 & $\mathbf{0 . 8 3 0}$ & -0.056 & 0.279 & 0.137 & 0.101 \\
CEITC_2 & $\mathbf{0 . 8 2 8}$ & -0.020 & 0.164 & 0.216 & 0.226 \\
CEITC_3 & $\mathbf{0 . 8 1 4}$ & -0.057 & 0.092 & 0.191 & 0.234 \\
CEITC_4 & $\mathbf{0 . 7 8 8}$ & -0.048 & 0.241 & 0.225 & 0.158 \\
CEITC_5 & $\mathbf{0 . 7 7 3}$ & -0.056 & 0.213 & 0.208 & 0.260 \\
CEITC_6 & $\mathbf{0 . 7 6 6}$ & -0.081 & 0.231 & 0.268 & 0.244 \\
CEITC_7 & $\mathbf{0 . 6 3 8}$ & -0.152 & 0.376 & 0.149 & -0.072 \\
GDUIT_1 & -0.047 & $\mathbf{0 . 9 2 9}$ & -0.021 & -0.034 & -0.083 \\
GDUIT_2 & -0.057 & $\mathbf{0 . 9 0 9}$ & -0.013 & -0.053 & -0.075 \\
GDUIT_3 & -0.026 & $\mathbf{0 . 9 0 1}$ & 0.009 & -0.058 & -0.074 \\
GDUIT_4 & -0.115 & $\mathbf{0 . 8 2 2}$ & -0.082 & -0.039 & -0.084 \\
GDUIT_5 & -0.038 & $\mathbf{0 . 7 5 5}$ & -0.181 & -0.138 & 0.036 \\
ARI_1 & 0.342 & -0.040 & $\mathbf{0 . 7 8 4}$ & 0.227 & 0.172 \\
ARI_2 & 0.359 & -0.029 & $\mathbf{0 . 7 6 0}$ & 0.176 & 0.238 \\
ARI_3 & 0.299 & -0.102 & $\mathbf{0 . 7 5 8}$ & 0.243 & 0.268 \\
ARI_4 & 0.248 & -0.160 & $\mathbf{0 . 7 1 2}$ & 0.213 & 0.344 \\
UCEI_1 & 0.264 & -0.117 & 0.161 & $\mathbf{0 . 8 0 8}$ & 0.286 \\
UCEI_2 & 0.293 & -0.106 & 0.195 & $\mathbf{0 . 8 0 2}$ & 0.227 \\
UCEI_3 & 0.317 & -0.059 & 0.230 & $\mathbf{0 . 7 1 7}$ & 0.232 \\
UCEI_4 & 0.296 & -0.119 & 0.436 & $\mathbf{0 . 6 2 7}$ & 0.267 \\
EUI_1 & 0.338 & -0.077 & 0.306 & 0.278 & $\mathbf{0 . 7 3 4}$ \\
EUI_2 & 0.296 & -0.063 & 0.330 & 0.338 & $\mathbf{0 . 7 2 7}$ \\
EUI_3 & 0.250 & -0.169 & 0.374 & 0.372 & $\mathbf{0 . 6 8 6}$ \\
EUI_4 & 0.269 & -0.131 & 0.240 & 0.479 & $\mathbf{0 . 6 3 7}$ \\
\hline
\end{tabular}

Firstly, the questionnaire investigates the network accessibility in school (NAS) and at home (NAH). Students generally have low scores on the school's e-learning environment (Figure 3). Students generally believe that it is not convenient to use e-learning equipment in schools, and schools do not support students to conduct e-learning. According to the interview materials, the restriction of students' use of electronic devices may be related to the school's consideration of both electronic devices hurting eyes and the low self-control of primary school students.

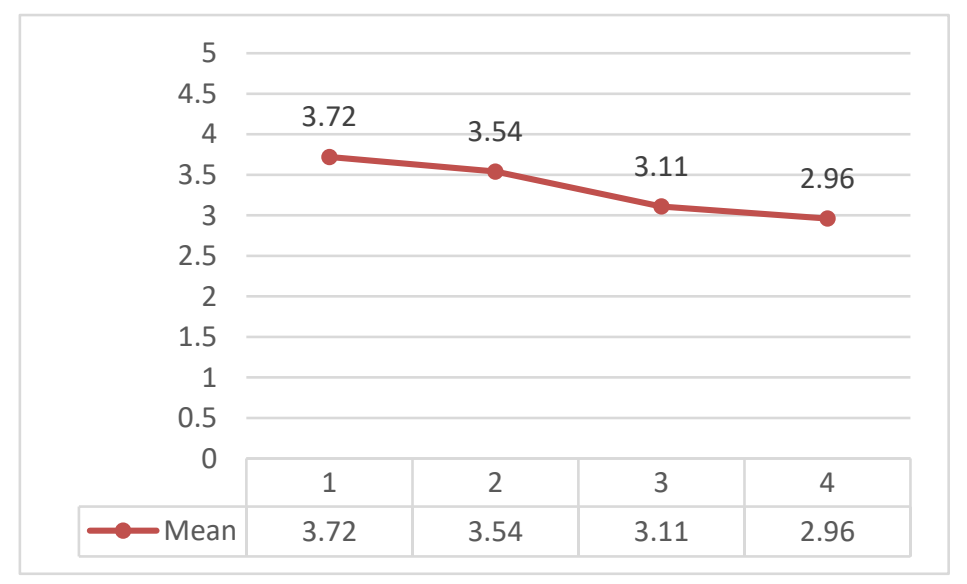

Figure 3. Network accessibility in school (NAS) 
Students generally think that the NAH is higher, and the scores show that students' home network environment scores are generally better, indicating that students' network constraints at home are not as strong as those at school. Statistical results show that a considerable number of students do not have their own online learning equipment.

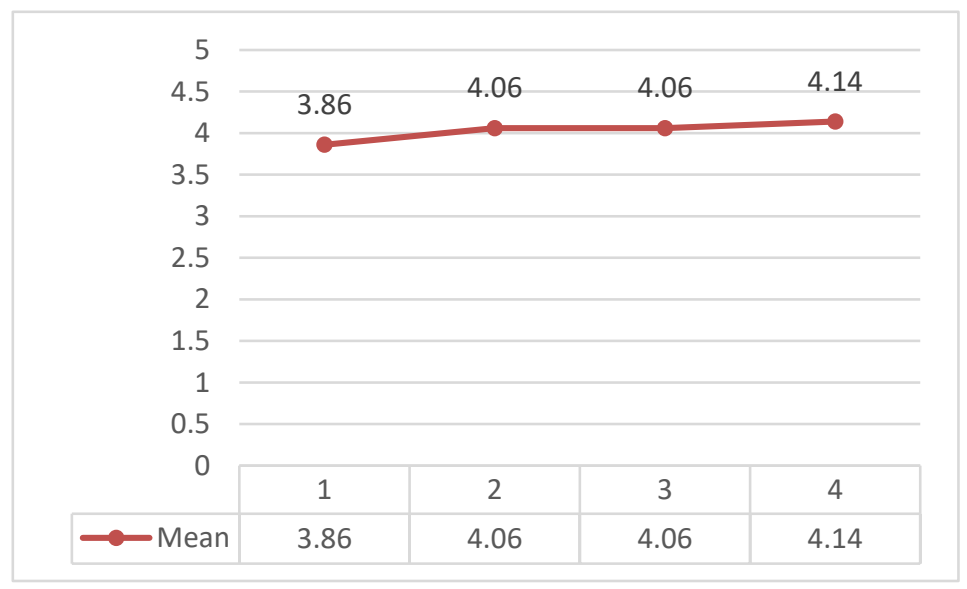

Figure 4. Network accessibility at home (NAH)

Table 7. Network access situation

\begin{tabular}{llr}
\hline Item & Mean & \multicolumn{1}{c}{ SD } \\
\hline NAS & 3.334 & 1.1657 \\
NAH & 4.032 & .783
\end{tabular}

It can be seen that the Mean values of each sub-dimension are ARI $=4.006$, EUI $=3.515$ and UCEI $=3.399$. With the gradual improvement of ability, students' scores gradually decline, which indicates that students' online learning behavior mostly stays at the low-level level, but does not reach the high-level level. Only the students in ARI dimension scored more than 4 points, while the students in the other four sub-dimensions scored less than 4 points, indicating that students are relatively low in information criticism and creativity. The CEITC of the students is 3.990, and there is still room for improvement. GDUIT score is 3.942, which indicates that students still have certain gender differences in the use of information, as shown in the post-face dimension item analysis.

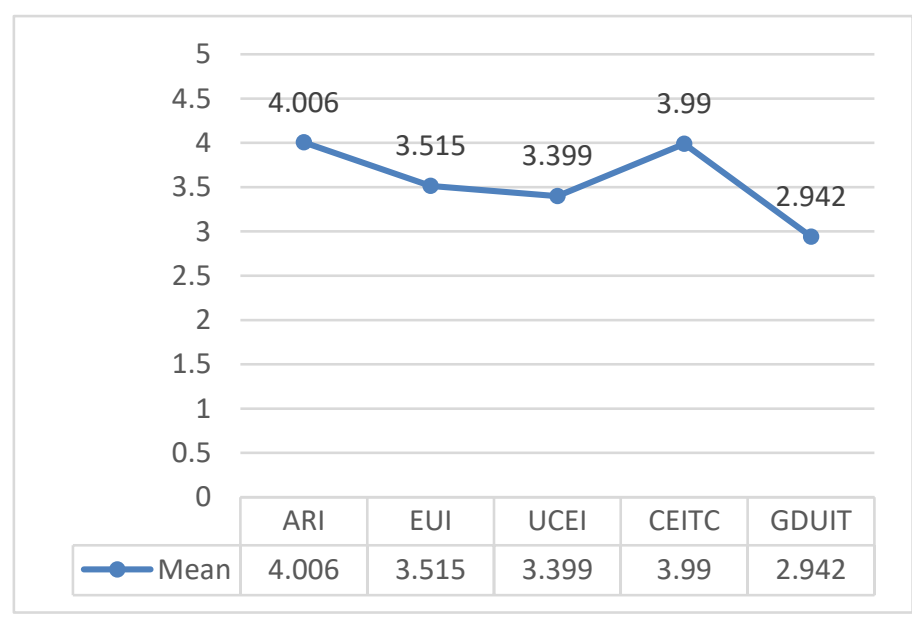

Figure 5. Mean value of each sub-dimension

\subsection{Results of Each Dimension}

\subsubsection{Results of ARI}

In the ARI dimension, most students report that they can find useful information, but they are weak in collecting information through multiple channels and solving problems through the network. 


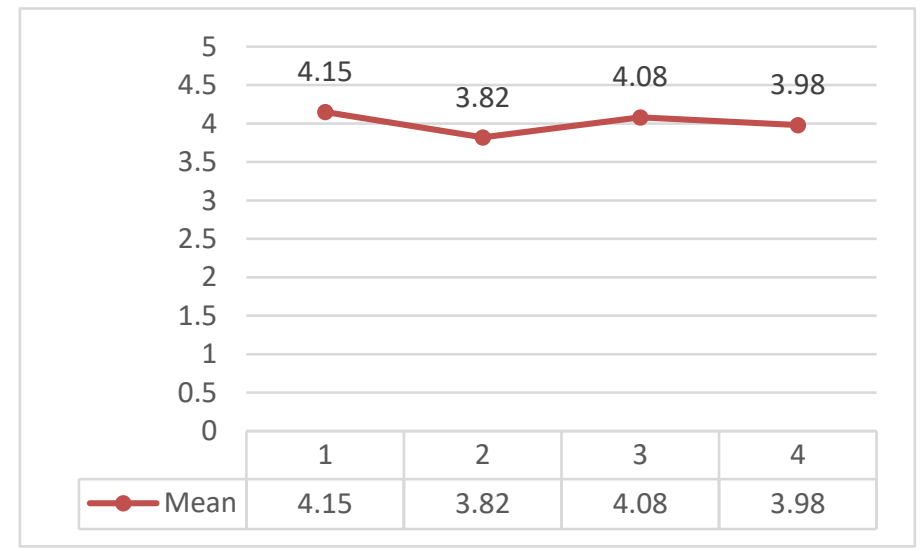

Figure 6. Score of each item in ARI

The scores of "I will use computers to collect information from different channels" and "I will find useful information through the Internet to solve problems in my life" did not reach 4 points. Students' ability to collect information needs to be improved, and their ability to transfer information to solve problems needs to be strengthened.

Combined with field interviews and research materials, it can be seen that students' ordinary study life is relatively tightly controlled, and the frequency of contact with the Internet and hardware equipment is not high, but students have a certain ability to retrieve information, such as when they need multiple solutions to one question.

"Sometimes when you have problems with your homework, the first step is to see if you can solve it, and the second step is to ask your parents, and then if you don't understand it, you can check the information. There are several students in our class who are all good at learning, all of whom are class cadres, so they can go to them to solve them; Besides, I can ask the teacher. We seldom look up information on the internet. (20210407-SY-S)"

"Questions with multiple solutions to one question can be asked to parents. If parents can only use one method, they can better understand this question by consulting the network materials. (20210409-SDF-S)"

Another example is to query information on the Internet. Some students use Baidu browser to query information:

"Usually, there are some tasks such as copying data. Sometimes, I will use the Internet to check some good statements and then extract them. Sometimes I copy from the book, but I can't find it, so I search for some good paragraphs on the Internet and copy them in the excerpts. (20210406-QLH-S\&T)"

"Sometimes, when I meet some tasks that need to check information, I will use my parents' mobile phones to check the required information, but the frequency is not very high. (20210407-DJ-S3)"

Some students use software to query information:

"I will use my mobile phone. Sometimes I will check the words I can't read on the Internet. Sometimes I will check the questions I can't read in advance. I like to use homework help APP, which can answer questions. (20210406-QLH-S\&T)"

From the students' words, we can judge that the students have the ability of information inquiry and retrieval, and the students have a positive evaluation of internet learning:

"Sometimes I use the browser on my mother's mobile phone to inquire information, which is very convenient. (20210406-QLH-S\&T)"

However, it can be seen that schools are quite conservative about students' use of electronic products. For some tasks that need to inquire about materials, teachers will let students inquire at home, and the inquired materials will be used directly in class, instead of checking and using them in class.

"If there is any activity to discuss the type, the teacher will ask us to consult the materials ourselves in advance. Mobile phones, which are electronic devices, can't be used in schools. They are mainly checked at home, then prepared, and then shared in schools. (202104048-BEF-S)"

One of the biggest reasons why students look up information at home is not as good as looking up information directly in the school classroom is that teachers can give students some guidance when they look up information in the school classroom, and they can correct it in time when they find that the content of students' inquiry is beside the point. However, in the home where students are far away from teachers, it is very likely that students do not really understand the Meaning of the question and make the inquiry topic yaw. 
On the whole, students' ability and awareness of using information are still weak. Even if they inquire about information on the Internet, they use paper and pen to keep records, instead of keeping them on electronic devices or somewhere.

"After using some learning websites, such as watching some documentaries, or watching special activities such as military parade, you will make corresponding notes in your notebook. (20210409-SDF-S)"

\subsubsection{Results of EUI}

The scores of questions in EUI are generally lower than 4 points, indicating that students do not understand information deeply enough, which may be related to students' less exposure to network information. Schools should build an appropriate learning environment rich in network information.

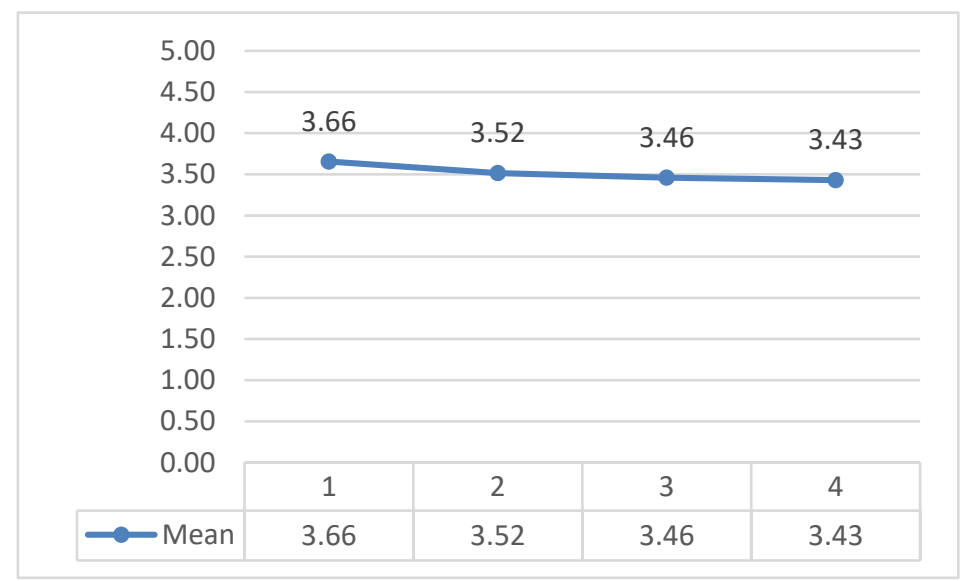

Figure 7. Score of each item in EUI

\subsubsection{Results of UCEI}

Students' scores in UCEI are generally low, they are unfamiliar with some operations on network equipment, and they do not use network equipment or software to actively promote their study. Their ability to communicate and solve problems with classmates through network equipment is not high.

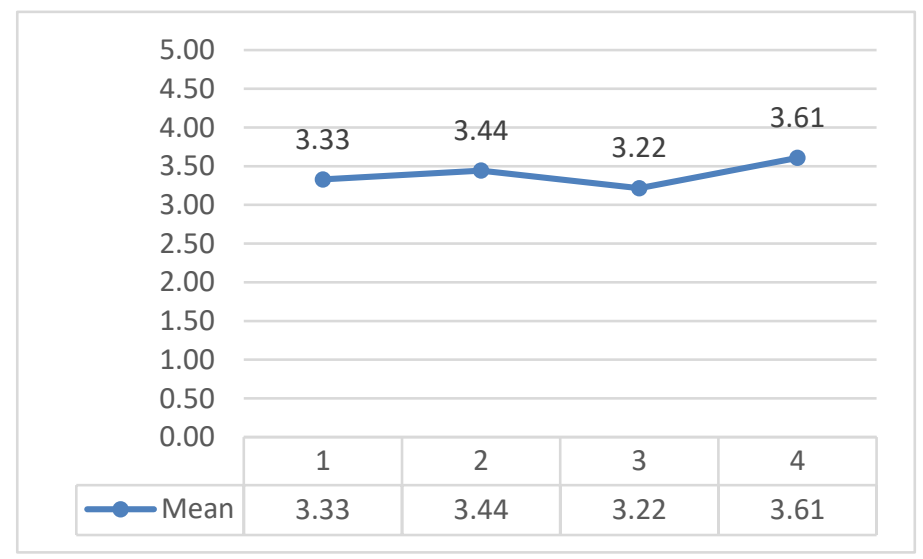

Figure 8. Score of each item in UCEI

\subsubsection{Results of CEITC}

The average score of the students in CEITC is 3.990 points, which is nearly 4 points, indicating that the information technology curriculum of the school is still in place. The first two questions examine students' attitudes towards taking information technology courses, and find that students generally agree to take information technology courses, and they think it is necessary to learn information-related operational knowledge. 


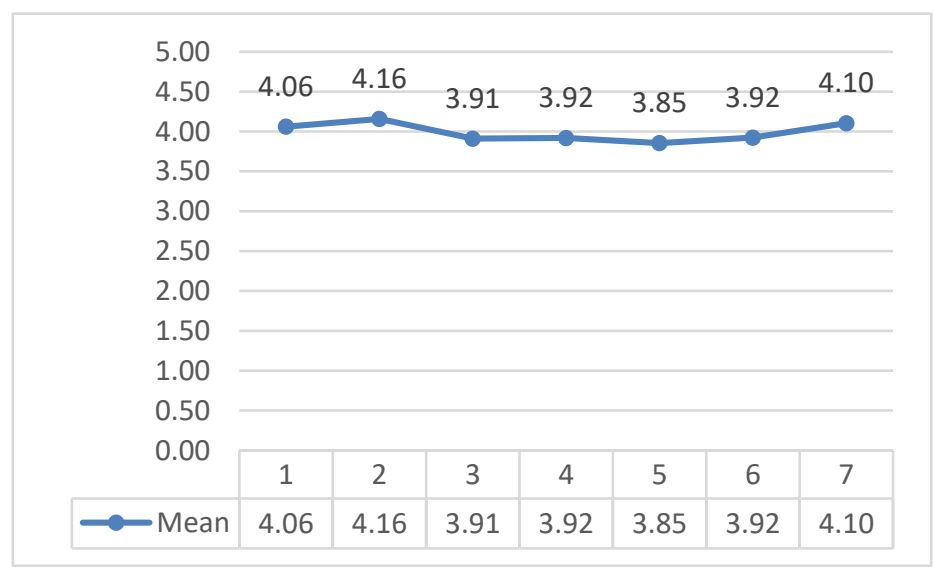

Figure 9. Score of each item in CEITC

According to the interview results, the information technology courses offered by the students in the lower grades of primary schools are relatively complete, while the students in the upper grades of primary schools generally report that the number of main courses has increased with the increase of grades, so the number of information technology courses has been reduced. In addition, from the conversation with the children, it can be seen that the information technology curriculum reform in our country has achieved certain results. Some senior primary school students said that they had less contact with information technology courses, while the lower primary school students had more contact.

"There are a few information technology classes. Our information technology classes are held once a week. We only started to get in touch with information technology in the first volume of the fourth grade. Like their third grade, they have already had information technology classes. They started to get in touch with information technology one semester before us, which we are quite envious of. I like playing games on weekends. Many of those games are binary ones and programming ones. I also think we should watch more movies. (20210407-SY-S)"

Students in the lower grades of primary school expressed their preference for the current teaching methods and information technology course contents:

"The teaching method in our school is very unique. Teachers will use games to guide us to learn the content of a certain class hour. I have access to some science and technology courses at school, such as robotics and programming. (20210406-QLH-S\&T)"

"Robot class, now there is a machine called robotstar, which can do some favorite things, like launching lasers and water bombs, but the premise that you want it to succeed is that you must set it up first, and you must also be able to program. We also learned a lot of knowledge in it. (202104048-BEF-S)"

According to the interview results, the information technology courses offered by the students in the lower grades of primary schools are relatively complete, while the students in the upper grades of primary schools generally report that the number of main courses has increased with the increase of grades, so the number of information technology courses has been reduced. In addition, from the conversation with the children, it can be seen that the information technology curriculum reform in our country has achieved certain results. Some senior primary school students said that they had less contact with information technology courses, while the lower primary school students had more contact.

"The information technology class is a little less, only one section per week, and we only started to get in touch with information technology in the first volume of the fourth grade. Students like the third grade have already had information technology classes, and they started to get in touch with information technology one semester before us, which we are quite envious of. I like playing games on weekends. Many of those games are binary ones and programming ones. I also think we should watch more movies. (20210407-SY-S)"

Students in the lower grades of primary school expressed their preference for the current teaching methods and information technology course contents:

"The teaching method in our school is very unique. Teachers will use games to guide us to learn the content of a certain class hour. I have access to some science and technology courses at school, such as robotics and programming. (20210406-QLH-S\&T)"

"Robot class, now there is a machine called robotstar, which can do some favorite things, like launching lasers and water bombs, but the premise that you want it to succeed is that you must set it up first, and you must also be able to program. We also learned a lot of knowledge in it. (202104048-BEF-S)" 
Some schools offer abundant extracurricular activities involving information technology for students, such as Qilihe Primary School's computer club activities for students, and "Primary School Lecture Hall" activities, etc., which need office software such as Word, PPT, EXCEL, etc. to assist:

"I joined the computer society. We first learn several parts of the computer, and after learning these parts, we begin to learn how to operate and use it. Finally, in the process of using these parts, we need to make a PPT by ourselves, which is very helpful to my daily life. There is a lecture hall for primary school students in our class. Every student shares his speech when he wakes up at noon. PPT makes my speech more exciting. (20210406-QLH-S\&T)"

"My favorite course is computer, which can let me know a lot about computer, like word documents, and some PPT or tables, which can make me use it more conveniently in my study. I have done some PPT on historical figures, and I will share it with you in the classroom. (20210406-QLH-S\&T)"

\subsubsection{Results of GDUIT}

First, the items in this dimension are scored reversely, and then the items are described and counted. The average score of this dimension is 2.942 , and the score is low, which shows that students do have stereotypes of gender differences in the process of using information technology.

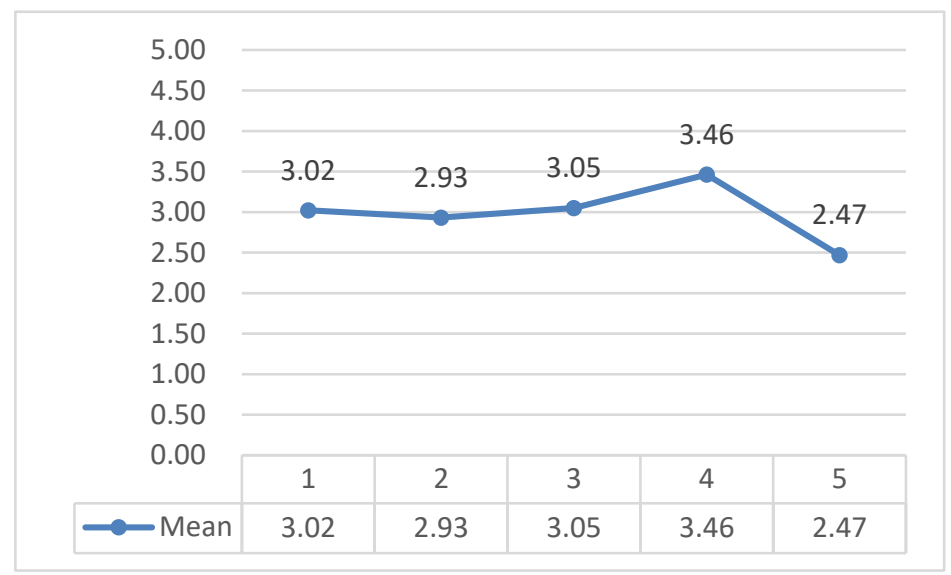

Figure 10. Score of each item in GDUIT

\subsection{Gender differences in information literacy}

The variance analysis of gender in total score shows that there is no significant difference between gender and total score. By analyzing gender differences in all dimensions, it is found that male scores are generally higher than female scores, but the higher part is not much. The scores of boys and girls in ARI and CEITC are close to 4 points. In addition, it can be seen from the histogram that the scores of boys and girls in EUI and UCEI are generally low, which also shows that boys and girls generally have less behavior on the application of high-level information technology. Univariate analysis of variance showed that there was no significant difference in scores between boys and girls in all dimensions.

Table 8 Gender differences in each dimension

\begin{tabular}{lllcccccccc}
\hline & \multicolumn{2}{c}{ ARI } & \multicolumn{2}{c}{ EUI } & \multicolumn{2}{c}{ UCEI } & \multicolumn{2}{c}{ CEITC } & \multicolumn{2}{c}{ GDUIT } \\
& \multicolumn{1}{c}{$\mathrm{M}$} & \multicolumn{1}{c}{$\mathrm{F}$} & \multicolumn{1}{c}{$\mathrm{M}$} & \multicolumn{1}{c}{$\mathrm{F}$} & $\mathrm{M}$ & \multicolumn{1}{c}{$\mathrm{F}$} & \multicolumn{1}{c}{$\mathrm{M}$} & $\mathrm{F}$ & $\mathrm{M}$ & \multicolumn{1}{c}{$\mathrm{F}$} \\
\hline Mean & 4.0159 & 3.9944 & 3.5432 & 3.4857 & 3.415 & 3.3808 & 4.005 & 3.974 & 2.701 & 3.199 \\
SD & 0.81159 & 0.81526 & 0.97526 & 0.96349 & 0.99962 & 0.98281 & 0.73499 & 0.74842 & 1.04777 & 1.03124 \\
\hline
\end{tabular}




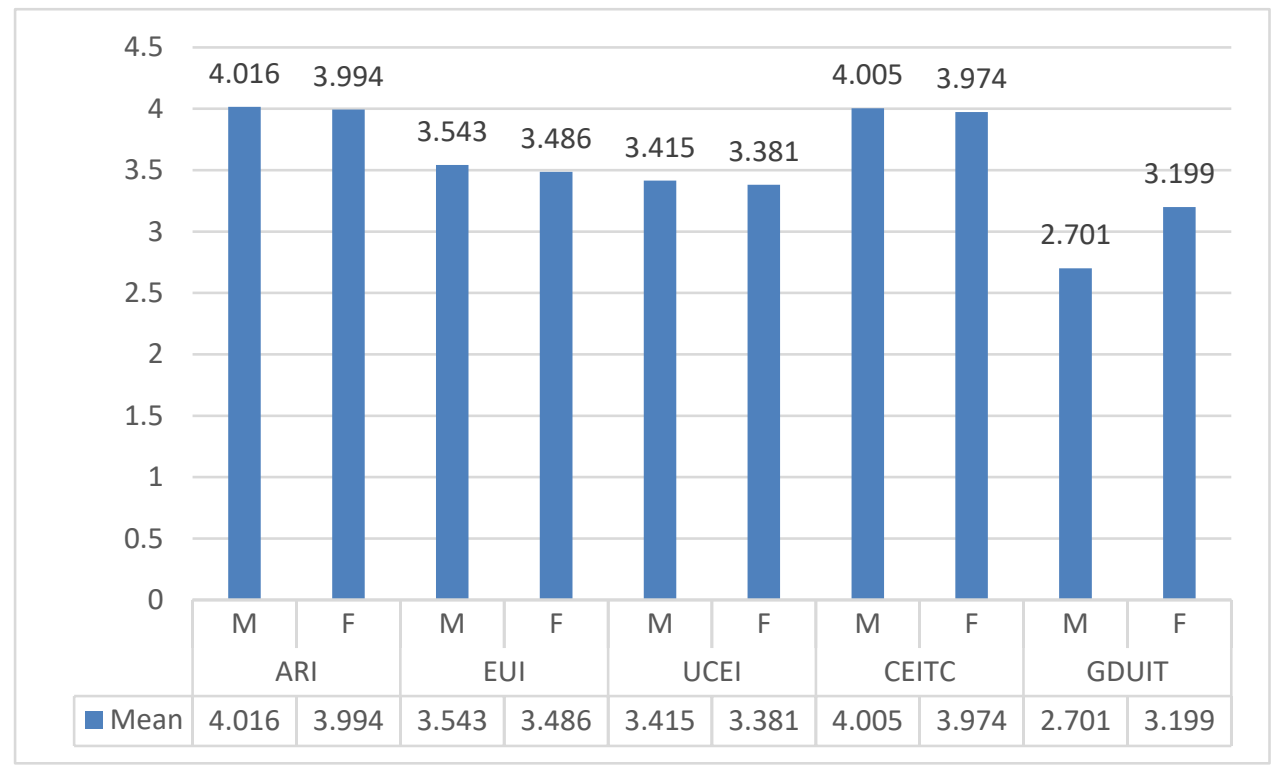

Figure 11. Average scores of different genders and dimensions

\subsection{Regional Differences in Information Literacy}

On the total score, analyze the variance of regions. It is found that there are significant differences between cities or counties and towns or villages. Urban students generally score higher than rural students. Combined with field investigation, it is found that schools in rural areas are not as complete as those in cities in terms of teachers, teaching and learning resources. The government should promote the allocation of rural resources and continue to increase investment in rural education.

Table 9. Multiple comparisons of regional differences in information literacy

\begin{tabular}{llcccc}
\hline \multirow{2}{*}{ city } & \multirow{2}{*}{ Standard error } & \multirow{2}{*}{ Significance } & \multicolumn{2}{c}{$95 \%$ confidence interval } \\
lower limit & upper limit \\
\hline \multirow{4}{*}{ county town } & county town & 5.55853 & .174 & -18.4557 & 3.3401 \\
& township & 1.13528 & .000 & 2.4008 & 6.8524 \\
& village & 2.07851 & .000 & 4.7507 & 12.9009 \\
& city & 5.55853 & .174 & -3.3401 & 18.4557 \\
& township & 5.66130 & .031 & 1.0850 & 23.2838 \\
& village & 5.92297 & .006 & 4.7712 & 27.9960 \\
& city & 1.13528 & .000 & -6.8524 & -2.4008 \\
\multirow{4}{*}{ village } & county town & 5.66130 & .031 & -23.2838 & -1.0850 \\
& village & 2.33950 & .073 & -.3876 & 8.7860 \\
& city & 2.07851 & .000 & -12.9009 & -4.7507 \\
& county town & 5.92297 & .006 & -27.9960 & -4.7712 \\
& township & 2.33950 & .073 & -8.7860 & .3876 \\
\hline
\end{tabular}

*. The significance level of Mean difference is 0.05 .

The analysis of regional variance in each dimension shows that there are significant differences between cities and towns, cities and villages, counties and villages, towns and villages in ARI, EUI, UCEI and CEITC dimensions, but there is no significant difference in GDUIT dimensions. 
Table 10. Average score of information literacy based on regional differences in each dimension

\begin{tabular}{llll}
\hline & region & Mean & SD \\
\hline \multirow{4}{*}{ ARI } & city & 4.0399 & 0.79036 \\
& county town & 4.1563 & 1.10952 \\
& township & 3.5928 & 0.90038 \\
& village & 3.2716 & 1.10351 \\
& city & 3.5291 & 0.96449 \\
EUI & county town & 4.2188 & 0.84976 \\
& township & 3.3441 & 0.96927 \\
& village & 3.1552 & 1.16963 \\
& city & 3.4082 & 0.98655 \\
UCEI & county town & 4.0625 & 1.02426 \\
& township & 3.2946 & 0.97983 \\
& village & 3.0603 & 1.23038 \\
& city & 4.0139 & 0.72961 \\
CEITC & county town & 4.0536 & 1.27533 \\
& township & 3.7065 & 0.73898 \\
& village & 3.4778 & 0.99751 \\
& city & 2.9367 & 1.06868 \\
& county town & 2.3167 & 1.41724 \\
GDUIT & township & 3.0482 & 1.05664 \\
& village & 2.9894 & 1.06889 \\
\hline \multirow{4}{*}{ ind } & & \\
& & & \\
& &
\end{tabular}

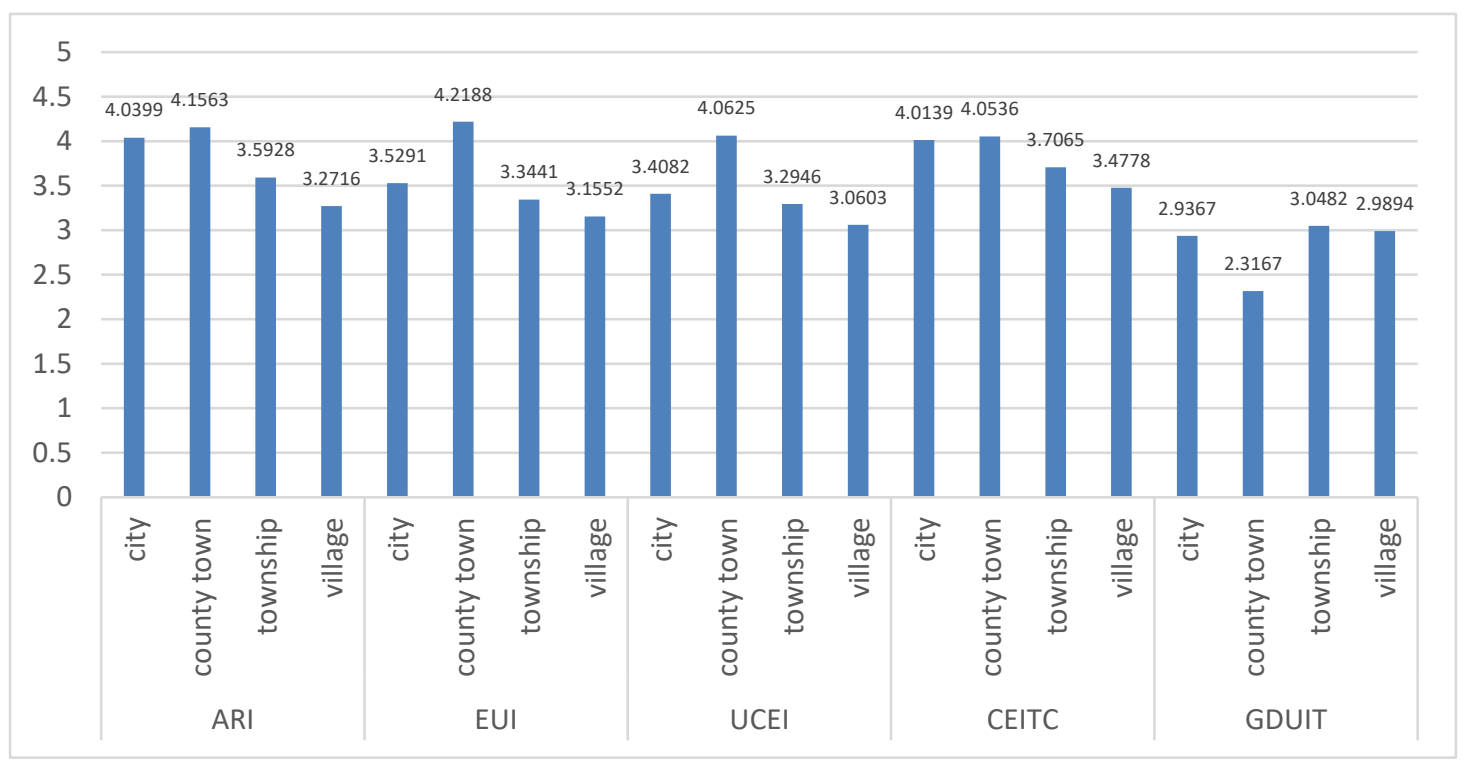

Figure 12. Average score of information literacy based on regional differences in each dimension

\subsection{The Influence of Parents' Occupation on Students' Information Literacy}

The influence of father's occupation on students' information literacy is as follows: there is a significant difference between father's occupation being an institution or enterprise, and father's occupation being an individual businessman or farmer; there is a significant difference between father's occupation being an individual businessman and father's occupation being a farmer. Generally speaking, students' information literacy scores will decrease with the decline of 
their father's professional prestige.

Table 11 The influence of father's occupation type on the average score of students' information literacy

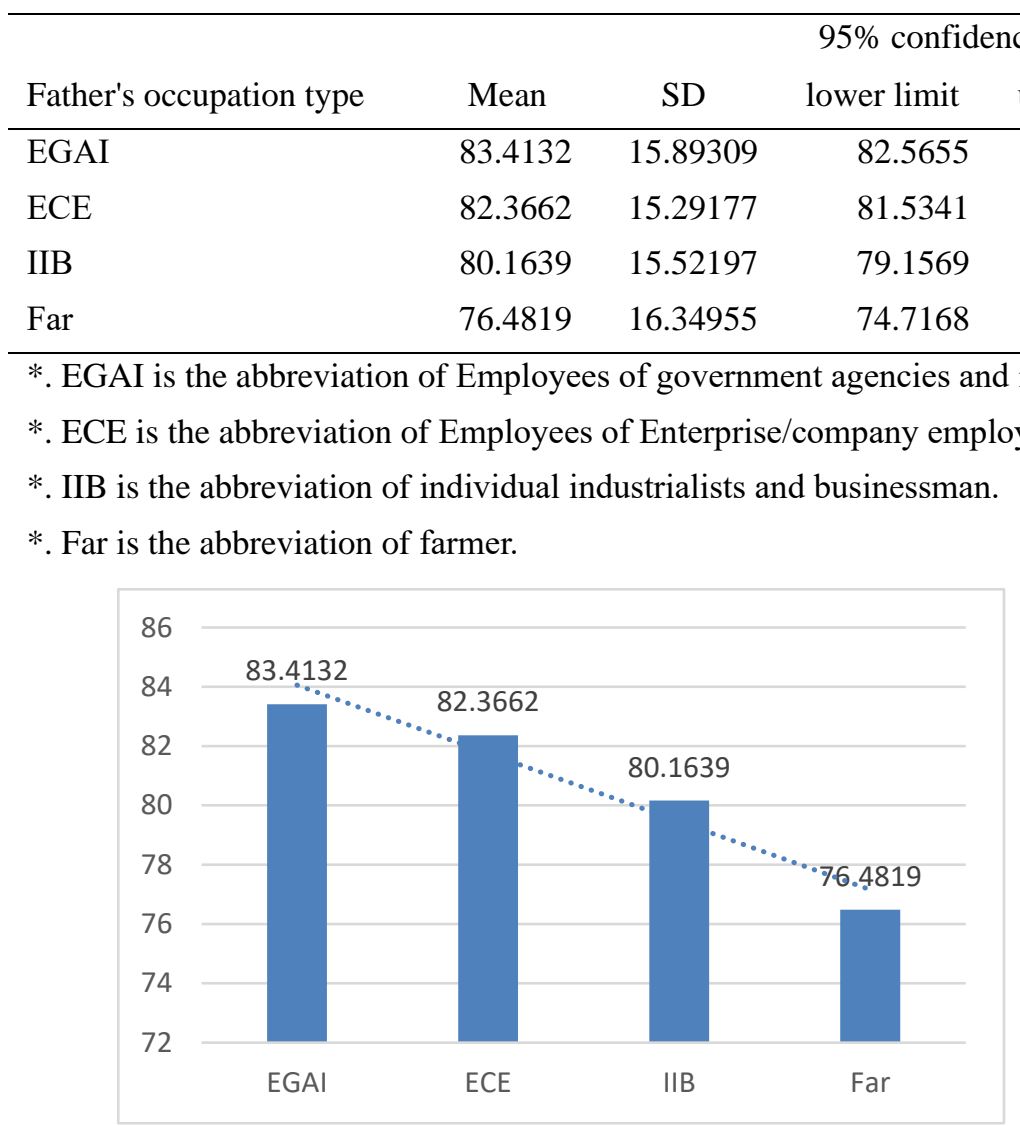

Figure 13. The influence of father's occupation type on the average score of students' information literacy

There are significant differences in the influence of father's occupation in every sub-dimension. From the overall trend, the scores of students' information literacy scores in each sub-dimension show a downward trend with the decline of their father's professional status and prestige. This trend is the same as the total score of students' information literacy.

Table 12. Father's occupational influence in each sub-dimension of the questionnaire.

\begin{tabular}{lllrrr}
\hline & & & \multicolumn{3}{c}{$95 \%$ confidence interval } \\
& & Mean & \multicolumn{1}{c}{ SD } & Lower limit & Upper limit \\
\hline \multirow{4}{*}{ ARI } & EGAI & 4.1055 & .80815 & 4.0624 & 4.1486 \\
& ECE & 4.0650 & .75928 & 4.0237 & 4.1063 \\
& IIB & 3.9309 & .79157 & 3.8795 & 3.9822 \\
& Far & 3.5708 & .93394 & 3.4700 & 3.6716 \\
& EGAI & 3.5754 & .98849 & 3.5227 & 3.6281 \\
EUI & ECE & 3.5435 & .95468 & 3.4915 & 3.5954 \\
& IIB & 3.4628 & .93840 & 3.4020 & 3.5237 \\
& Far & 3.3057 & 1.00579 & 3.1971 & 3.4143 \\
& EGAI & 3.4793 & .99082 & 3.4265 & 3.5321 \\
UCEI & ECE & 3.3977 & .98371 & 3.3442 & 3.4512 \\
& IIB & 3.3429 & .97253 & 3.2798 & 3.4060 \\
& Far & 3.2252 & 1.04702 & 3.1121 & 3.3382 \\
CEITC & EGAI & 4.0703 & 0.73123 & 4.0313 & 4.1093
\end{tabular}




\begin{tabular}{llllll}
\multirow{1}{*}{ ECE } & 4.0441 & 0.71438 & 4.0052 & 4.0829 \\
IIB & 3.9102 & 0.72754 & 3.8630 & 3.9574 \\
GDUIT & Far & 3.6717 & 0.82022 & 3.5831 & 3.7602 \\
& EGAI & 2.9215 & 1.10151 & 2.8628 & 2.9803 \\
& ECE & 2.8914 & 1.05650 & 2.8340 & 2.9489 \\
& IIB & 3.0381 & 1.05055 & 2.9699 & 3.1062 \\
& Far & 2.9587 & 1.02032 & 2.8486 & 3.0689 \\
\hline
\end{tabular}

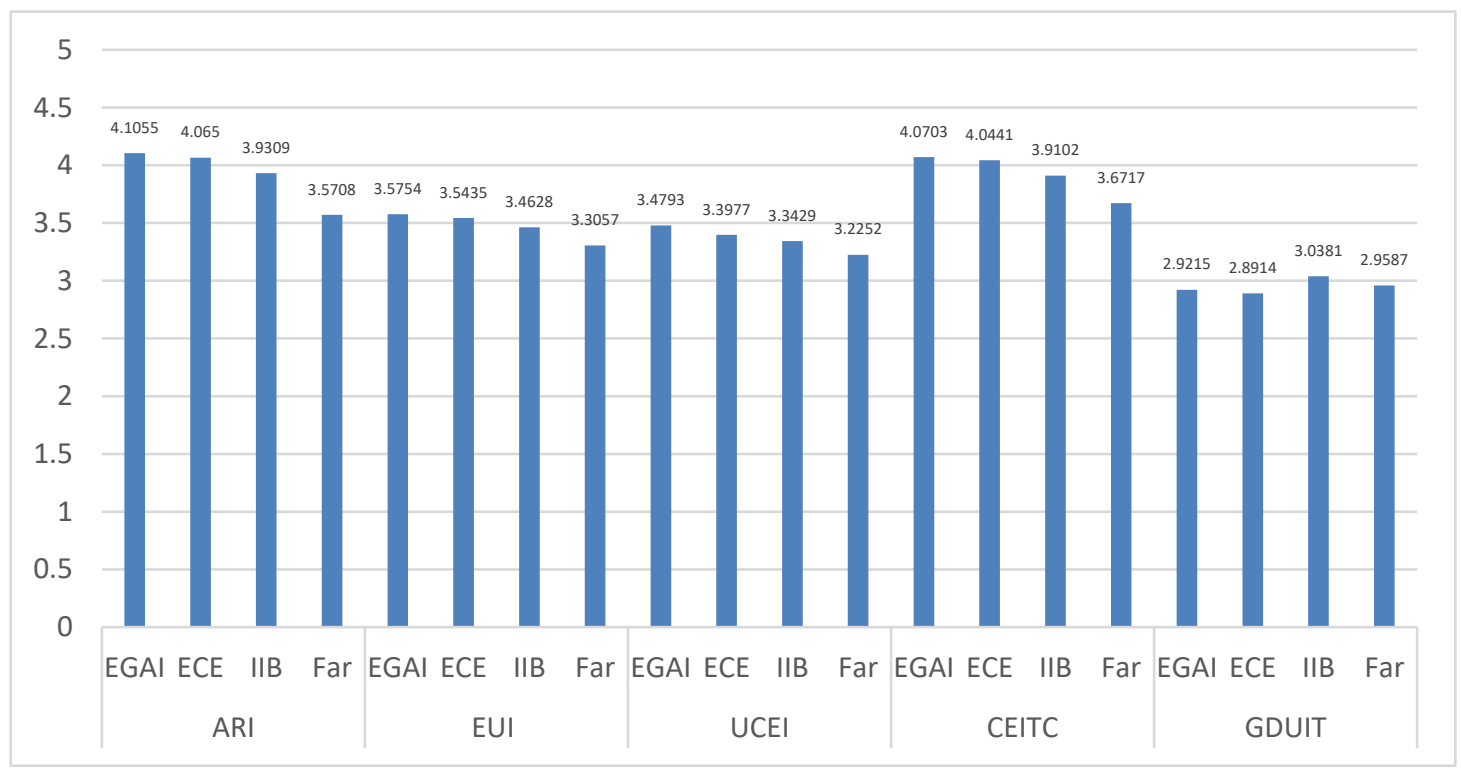

Figure 14. Average score of father's occupation in each sub-dimension

The influence of mother occupation on students' information literacy is as follows: there is a significant difference between mother occupation being an institution or enterprise, company personnel and mother occupation being an individual businessman or farmer, and there is a significant difference between mother occupation being an individual businessman and mother occupation being a farmer. Generally speaking, students' information literacy scores will decrease with the decline of their mothers' professional prestige.

Table 13 The influence of mother's occupation type on the average score of students' information literacy

\begin{tabular}{lcrrr}
\hline \multirow{2}{*}{ Mother's occupation type } & Mean & Standard deviation & Lower limit & Upper limit \\
\hline EGAI & 83.1366 & 15.78085 & 82.2838 & 83.9893 \\
ECE & 82.7118 & 15.29872 & 81.8696 & 83.5540 \\
IIB & 80.4294 & 15.43571 & 79.4150 & 81.4437 \\
Far & 76.9405 & 16.74172 & 75.3347 & 78.5462 \\
\hline
\end{tabular}




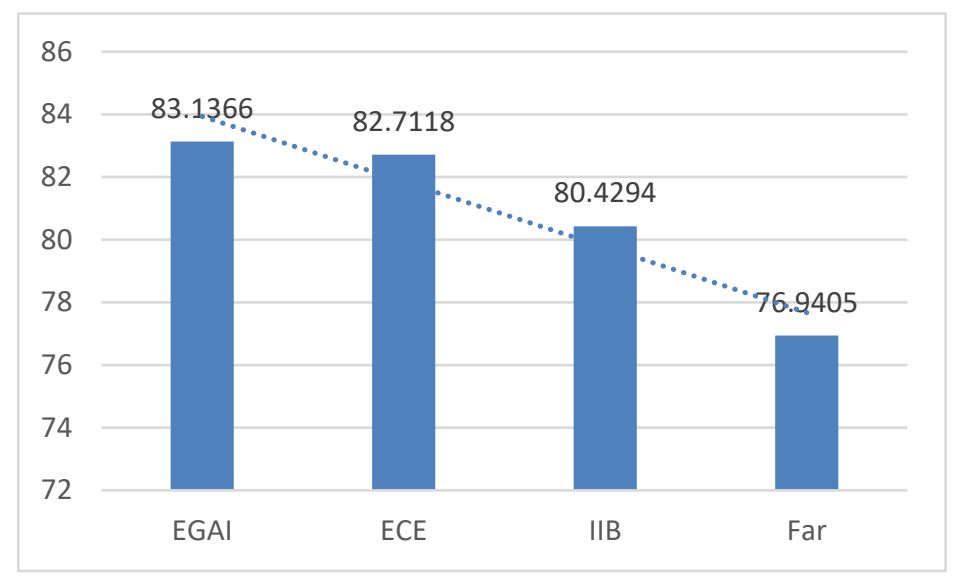

Figure 15. The influence of mother's occupation type on the average score of students' information literacy

There are significant differences in the influence of mother's occupation in every sub-dimension. From the overall trend, the scores of students' information literacy in each sub-dimension show a downward trend with the decline of their father's professional status and reputation.

Table 14. Mother's occupational influence in each sub-dimension of the questionnaire

\begin{tabular}{rlrrrr}
\hline & & & \multicolumn{3}{c}{ 95\% confidence interval } \\
& & Mean & \multicolumn{1}{c}{ SD } & Lower limit & Upper limit \\
\hline \multirow{4}{*}{ ARI } & EGAI & 4.0888 & .79589 & 4.0458 & 4.1318 \\
& ECE & 4.0803 & .75497 & 4.0388 & 4.1219 \\
& IIB & 3.9706 & .78811 & 3.9188 & 4.0224 \\
& Far & 3.5923 & .95137 & 3.5010 & 3.6835 \\
& EGAI & 3.5668 & .98320 & 3.5136 & 3.6199 \\
EUI & ECE & 3.5480 & .94997 & 3.4957 & 3.6003 \\
& IIB & 3.4829 & .92958 & 3.4218 & 3.5440 \\
& Far & 3.3244 & 1.04592 & 3.2241 & 3.4247 \\
& EGAI & 3.4528 & .99013 & 3.3993 & 3.5063 \\
UCEI & ECE & 3.4258 & .97862 & 3.3719 & 3.4797 \\
& IIB & 3.3719 & .96316 & 3.3086 & 3.4352 \\
& Far & 3.2018 & 1.06874 & 3.0993 & 3.3043 \\
& EGAI & 4.0569 & .73628 & 4.0171 & 4.0967 \\
CEITC & ECE & 4.0619 & .70557 & 4.0230 & 4.1007 \\
& IIB & 3.9214 & .71168 & 3.8746 & 3.9681 \\
& Far & 3.7092 & .84266 & 3.6284 & 3.7900 \\
& EGAI & 2.9522 & 1.09815 & 2.8929 & 3.0116 \\
& ECE & 2.8969 & 1.06649 & 2.8382 & 2.9557 \\
& IIB & 2.9766 & 1.03065 & 2.9089 & 3.0443 \\
& Far & 2.9728 & 1.06348 & 2.8708 & 3.0748 \\
\hline
\end{tabular}




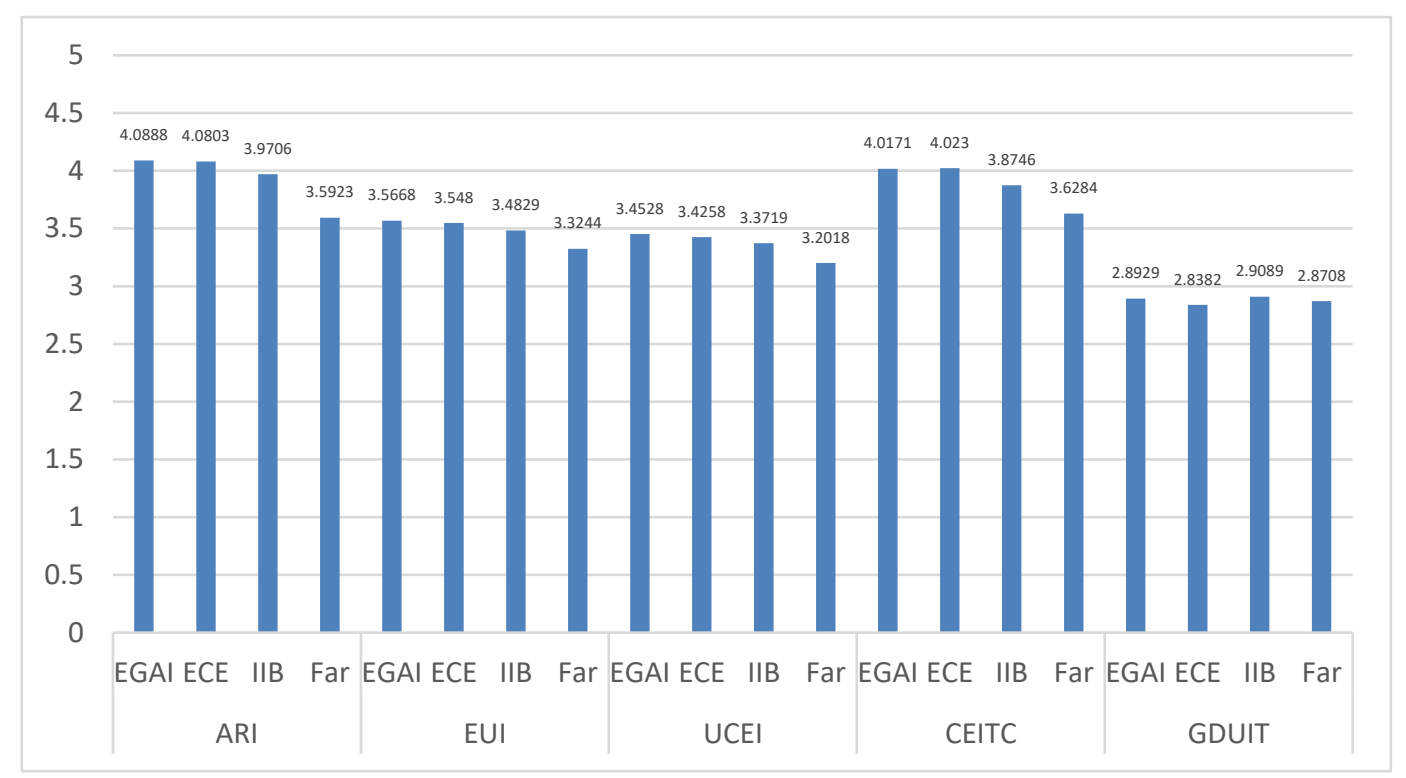

Figure 16. Average score of mother's occupation in each sub-dimension

The influence of father's occupation and mother's occupation on students' information literacy scores is similar, which indicates that the influence of parents' occupation on children's information literacy development is roughly the same. Parents with high professional status and prestige have relatively high scores in ARI, EUI, UCEI and CEITC. Parents with higher professional status and prestige may have higher horizon and income than parents with lower professional status, which has a direct impact on students, such as access to educational resources, and an indirect impact, such as parents' opinions on open supervision, thus affecting students' exposure to information technology.

\subsection{The Influence of Parents' Educational Background on Students' Information Literacy}

As can be seen from the statistics and figures, students' information literacy scores will increase with their parents' educational background.

Table 15. Average score of information literacy of students with different parents' educational backgrounds

\begin{tabular}{llll}
\hline $\begin{array}{l}\text { educational } \\
\text { background }\end{array}$ & parent & Mean & SD \\
\hline PS & father & 76.3602 & 17.44941 \\
& mother & 76.9951 & 17.89277 \\
SSTSS & father & 79.2009 & 15.5154 \\
& mother & 79.3762 & 15.54824 \\
CU & father & 82.6203 & 15.41553 \\
& mother & 82.8686 & 15.36744 \\
MPGS & father & 83.4643 & 16.15959 \\
& mother & 82.7990 & 16.08041 \\
\hline
\end{tabular}

*. The significance level is $0.05 \mathrm{SB}$ is the abbreviation of primary school and below.

*. PS is the abbreviation of primary school

*. SSTSS is the abbreviation of secondary school or technical secondary school

*. CU is the abbreviation of college or undergraduate

*. MPGS is the abbreviation of master or PhD graduate students 


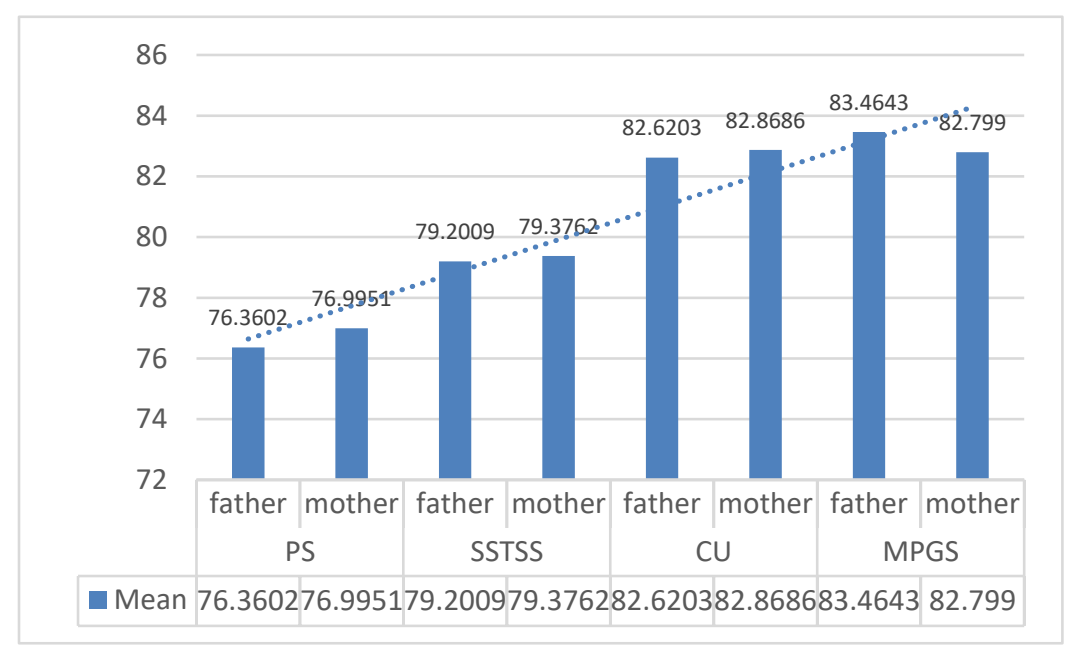

Figure 17. Histogram of average score of information literacy of students with different parents' education background One-way ANOVA shows that the influence of parent's educational background is significantly different in all sub-dimensions. In each sub-dimension, students' information literacy scores will increase with the increase of their parent's educational background.

Table 16. The significance of the influence of parent's educational background on students' information literacy in each dimension

\begin{tabular}{lllllll}
\hline & parents & ARI & EUI & UCEI & CEITC & GDUIT \\
\hline \multirow{2}{*}{ F } & father & 46.999 & 6.075 & 5.97 & 27.393 & 2.791 \\
& mother & 43.476 & 6.152 & 4.720 & 28.950 & 3.317 \\
\multirow{2}{*}{ Sig. } & father & 0.000 & 0.000 & 0.000 & 0.000 & 0.039 \\
& mother & 0.000 & 0.000 & 0.003 & 0.000 & 0.019 \\
\hline
\end{tabular}

*. The significance level is 0.05 .

Table 17. The average score of the influence of different fathers' educational backgrounds on students' information literacy in each dimension

\begin{tabular}{rlrrrr}
\hline & & & & & $95 \%$ confidence interval \\
& & Mean & \multicolumn{1}{c}{ SD } & Lower limit & Upper limit \\
\hline \multirow{5}{*}{ ARI } & PS & 3.5419 & .93384 & 3.3966 & 3.6873 \\
& SSTSS & 3.8159 & .83776 & 3.7614 & 3.8703 \\
& CU & 4.0820 & .76224 & 4.0497 & 4.1143 \\
& MPGS & 4.1274 & .82562 & 4.0655 & 4.1892 \\
& PS & 3.3292 & 1.03999 & 3.1673 & 3.4911 \\
EUI & SSTSS & 3.4281 & .93529 & 3.3673 & 3.4889 \\
& CU & 3.5481 & .96436 & 3.5072 & 3.5890 \\
& MPGS & 3.5728 & 1.00390 & 3.4976 & 3.6480 \\
& PS & 3.2252 & 1.06037 & 3.0601 & 3.3902 \\
UCEI & SSTSS & 3.3065 & .96367 & 3.2439 & 3.3692 \\
& CU & 3.4297 & .99436 & 3.3876 & 3.4718 \\
& MPGS & 3.4636 & .99183 & 3.3893 & 3.5379 \\
& PS & 2.9650 & 1.05190 & 2.8013 & 3.1287 \\
CEITC & SSTSS & 3.0104 & 1.03875 & 2.9429 & 3.0780 \\
& CU & 2.8983 & 1.07145 & 2.8529 & 2.9437 \\
& MPGS & 2.9823 & 1.10055 & 2.8998 & 3.0647 \\
& PS & 3.6752 & .90773 & 3.5340 & 3.8165 \\
GDUIT & SSTSS & 3.8534 & .73339 & 3.8057 & 3.9011 \\
& CU & 4.0593 & .71229 & 4.0291 & 4.0894 \\
& MPGS & 4.0295 & .75685 & 3.9728 & 4.0862 \\
\hline
\end{tabular}




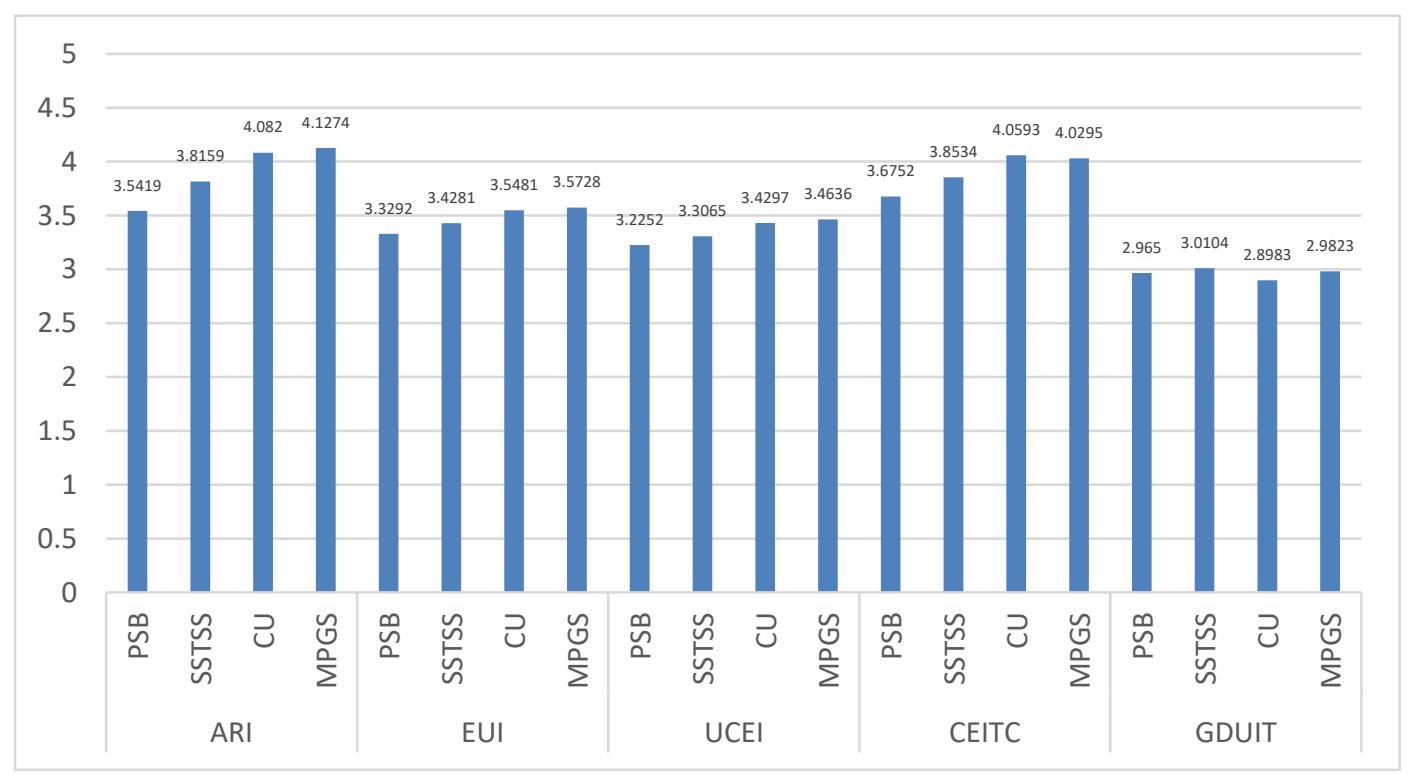

Figure 18. Histogram of the average score of the influence of different fathers' educational backgrounds on students' information literacy in various dimensions

Table 18. The average score of the influence of different mothers' educational backgrounds on students' information literacy in each dimension

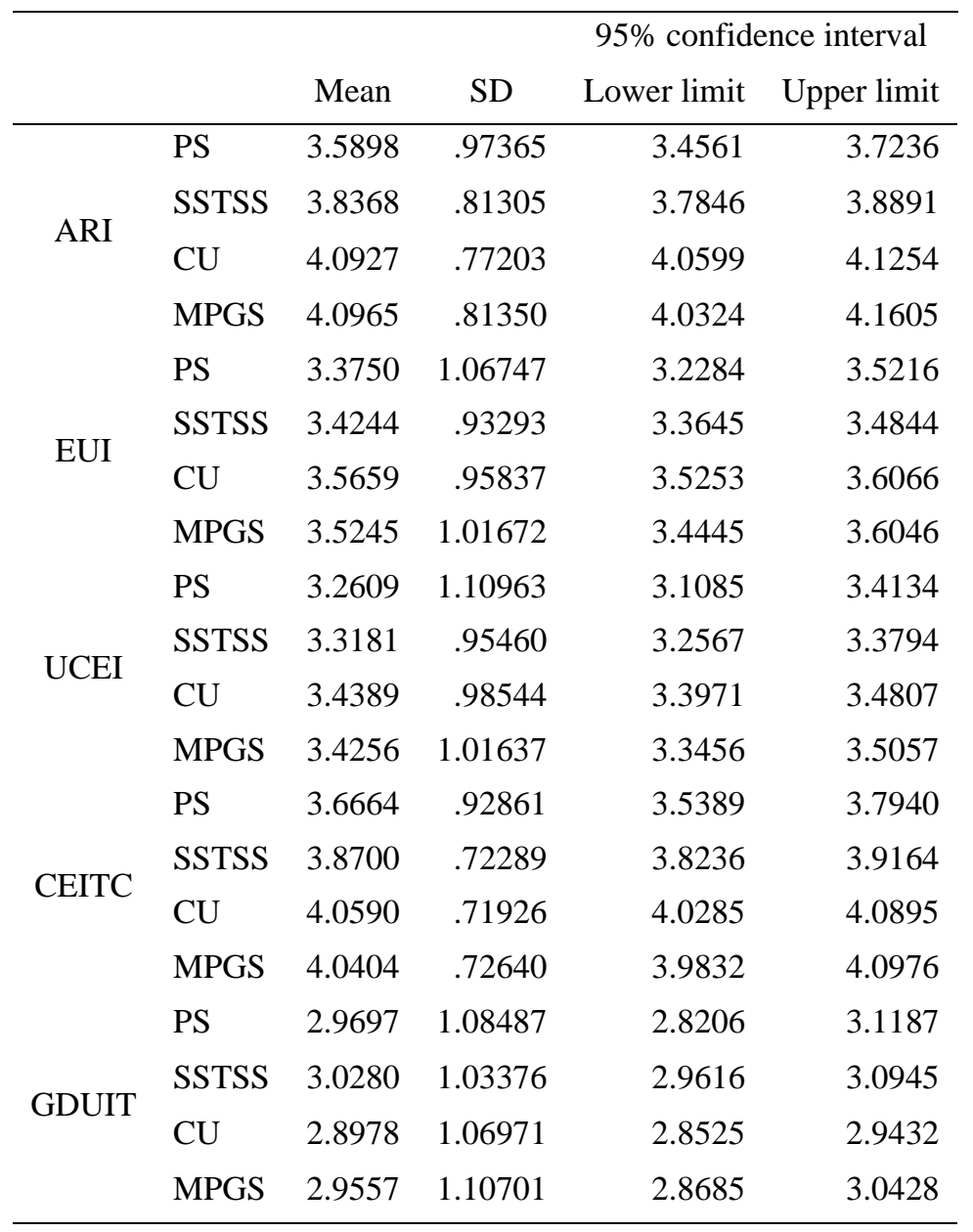




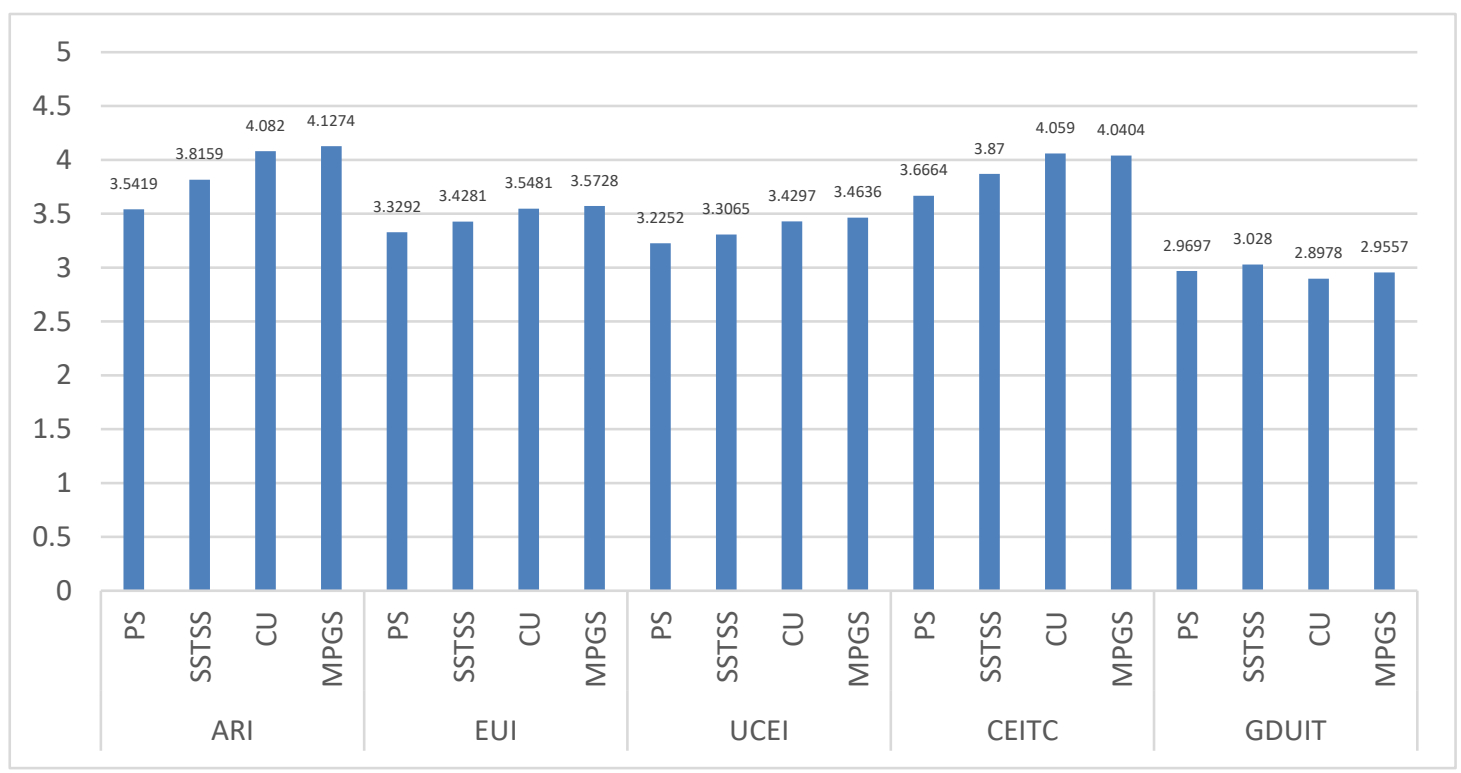

Figure 19. Histogram of the average score of the influence of different mothers' educational backgrounds on students' information literacy in various dimensions

The influence of father's and mother's educational background on students' information literacy scores is similar, which indicates that the influence of parents' occupation on children's information literacy development is roughly the same. Parents with higher education level have higher scores on ARI, EUI, UCEI, CEITC, GDUIT.

\subsection{The influence of the number of children at home on students' information literacy}

The variance analysis of the number of children at home shows that there is a significant difference between the influence of $1 / 2$ children in the home on students' information literacy and the influence of $3 / 4$ children in the home on students' information literacy. There are $1 / 2$ children in the family whose information literacy scores are above $80,3 / 4$ children in the family whose information literacy scores are below 80, and 5 or more children whose information literacy scores are above 80 . Further analysis shows that the number of children in the home is significantly affected by parents' occupation and parents' educational background, so the number of children at home can be used as an intermediary variable for parents' occupation and parents' educational background to influence students' information literacy. (The influence mechanism is shown in Figure 21. )

Table 19 Average score of information literacy of students with different number of children in their families

\begin{tabular}{lrccrr}
\hline & & & & \multicolumn{2}{c}{$95 \%$ confidence interval } \\
the number of children at home & \multicolumn{1}{c}{$\mathrm{N}$} & Mean & SD & Lower limit & Upper limit \\
\hline One & 1774 & 82.8963 & 15.51131 & 82.1740 & 83.6186 \\
Two & 850 & 83.1012 & 15.89887 & 82.0308 & 84.1715 \\
Three & 1087 & 79.2953 & 15.44825 & 78.3759 & 80.2147 \\
Four & 159 & 77.6604 & 16.93503 & 75.0078 & 80.3130 \\
Five & 18 & 83.2222 & 20.44089 & 73.0572 & 93.3872 \\
\hline
\end{tabular}




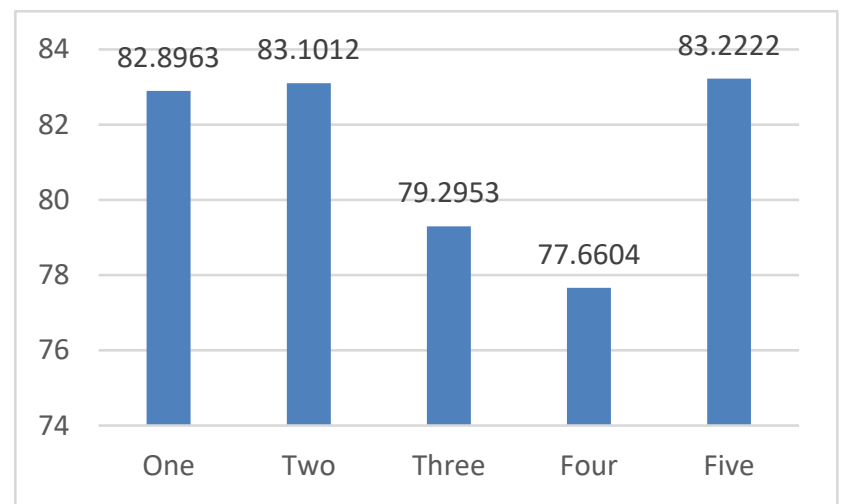

Figure 20. Histogram of average score of students' information literacy with different number of children in home Table 20. Differences in information literacy scores of students with different numbers of children in different families

\begin{tabular}{|c|c|c|c|c|c|}
\hline \multirow{2}{*}{\multicolumn{2}{|c|}{ The number of children at home }} & \multirow{3}{*}{$\begin{array}{r}\text { Standard error } \\
.65377\end{array}$} & \multirow{3}{*}{$\begin{array}{r}\text { significance } \\
.754\end{array}$} & \multicolumn{2}{|c|}{$95 \%$ confidence interval } \\
\hline & & & & \multirow{2}{*}{$\begin{array}{r}\text { Lower limit } \\
-1.4867\end{array}$} & \multirow{2}{*}{$\begin{array}{r}\text { Upper limit } \\
1.0769\end{array}$} \\
\hline 1 & 2 & & & & \\
\hline & 3 & .60367 & .000 & 2.4174 & 4.7845 \\
\hline & 4 & 1.29739 & .000 & 2.6923 & 7.7795 \\
\hline & 5 & 3.71268 & .930 & -7.6049 & 6.9530 \\
\hline \multirow[t]{4}{*}{2} & 1 & .65377 & .754 & -1.0769 & 1.4867 \\
\hline & 3 & .71758 & .000 & 2.3990 & 5.2127 \\
\hline & 4 & 1.35416 & .000 & 2.7859 & 8.0957 \\
\hline & 5 & 3.73289 & .974 & -7.4397 & 7.1976 \\
\hline \multirow[t]{4}{*}{3} & 1 & .60367 & .000 & -4.7845 & -2.4174 \\
\hline & 2 & .71758 & .000 & -5.2127 & -2.3990 \\
\hline & 4 & 1.33069 & .219 & -.9740 & 4.2438 \\
\hline & 5 & 3.72444 & .292 & -11.2290 & 3.3751 \\
\hline \multirow[t]{4}{*}{4} & 1 & 1.29739 & .000 & -7.7795 & -2.6923 \\
\hline & 2 & 1.35416 & .000 & -8.0957 & -2.7859 \\
\hline & 3 & 1.33069 & .219 & -4.2438 & .9740 \\
\hline & 5 & 3.89747 & .154 & -13.2031 & 2.0794 \\
\hline \multirow[t]{4}{*}{5} & 1 & 3.71268 & .930 & -6.9530 & 7.6049 \\
\hline & 2 & 3.73289 & .974 & -7.1976 & 7.4397 \\
\hline & 3 & 3.72444 & .292 & -3.3751 & 11.2290 \\
\hline & 4 & 3.89747 & .154 & -2.0794 & 13.2031 \\
\hline
\end{tabular}




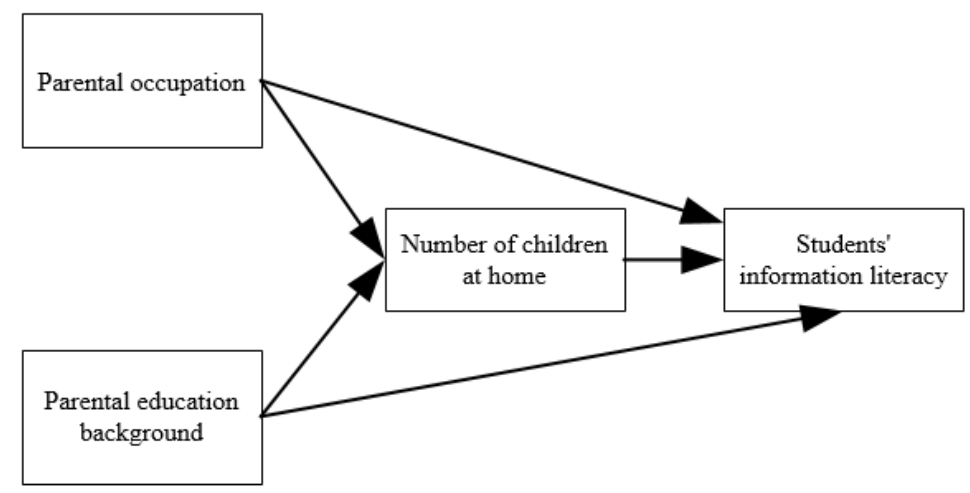

Figure 21. Illustration of the influence of parents' occupation and educational background and the number of children at home on students' information literacy in the west of China

\section{Discussion}

\subsection{Education Gap Between Urban and Rural Areas}

On the whole, there is a big gap in education level between urban and rural areas, which is mainly reflected in the quantity of resources and materials, the allocation of hardware and equipment and the support of teachers' professional development.

\subsubsection{The Shortage of Rural Educational Resources and Equipment Is Particularly Prominent}

Not only from the above questionnaire results, it can be concluded that there is a significant gap between urban and rural school education in western China, but also the researchers found that there are obvious differences between urban and rural education in many aspects through in-depth interviews.

Urban schools are well equipped and have enough teachers who have the ability to think deeply about how to integrate information technology into the classroom, while primary schools in rural areas are relatively weak. Compared with the development of more innovative school-based curriculum, how to start a well-regulated national curriculum is still the top priority for the construction of curriculum system in these primary schools. Due to the shortage of teachers in Wushengyi Primary School, each teacher has to take on the daily teaching work of multiple grades, classes or disciplines at the same time. And the school teaching hardware configuration is backward. In addition, in an interview at the school, a sixth-grade student told the researcher that he had only been in the science classroom once in six years.

"Most science classes are occupied by Chinese teachers ... Science books in our class are also very scarce, and science books are also scarce. Most of our classes will be crowded in a chair, and several people will read a book. (20210408-WSY-S)"

In addition to science courses, music, art, morality and legal system are frequently occupied. Teachers' attitude is "willing", which is also because the number of teachers is not enough. It is a common problem in all rural primary schools that the curriculum is not fully provided. Therefore, it can be considered that schools in rural areas do not have the ability to further develop the curriculum system and resources.

However, the practice of this kind of information technology integration teaching is in the initial stage in both urban and rural schools, and the required equipment is small. In most cases, classroom teaching in schools still relies on commonly used electronic whiteboard, projector and other technical Means, so the innovation of classroom teaching driven by technology is insufficient.

\subsubsection{The Development of Rural Teachers Lacks Support}

Digital natives are not necessarily information literate, and that IL should be promoted with courses based on IL standards.(Rosman et al.,2016) Therefore, teacher professional development should be supported. However, the resources available for teaching research in rural schools are very limited. Besides, it is difficult to retain outstanding and qualified teachers in rural schools.

"During the epidemic, we discovered that the lack of quality of our teachers was due to a shortage of resources.

Therefore, I wanted to find some materials on teaching online. However, such material was not easily available, and I didn't find the desired resources. (20210407-LJX-P)" 
At present, the support for the development of teachers in rural elementary schools is low, which cannot fully satisfy the needs of teachers for professional development. Although at the policy level, the state adopts concept "Tilting to the countryside" to promote the development of rural compulsory education, it is hard to share educational teacher resources high-quality between urban and rural areas effectively, due to the barriers of the urban-rural space-time relationship. To promote the interaction of urban and rural schools and the interactive sharing of resources, mechanisms based on information technology is a promising solution, which thus needs further investigation.

\subsection{Parents' Restrictions on Students' Use of Electronic Devices}

On the whole, parents did not actively support students' contact with Internet. Specifically, most parents are very resistant to their children's use of networked equipment:

"I don't like to use these things. My mother had a TV at home before I was born. But she threw the TV away after my birth, and I didn't watch TV until I was 4 years old. Besides, my mother seldom allows me to use the mobile phone, and thus, I haven't played any games. (20210407-SY-S)"

For the other small portion of parents, although they will provide their children with electronic products, they still monitor their children's use of electronic devices by themselves or with the help of monitoring software, such as the youth mode and remote control software.

"My mother will give me some time to use the electronic equipment. If the time is up, the equipment will automatically lock or exit, and you can use the equipment again after you have a rest. Besides, for the phone-watch, my mother disables the use of the watch during class time through an application. Therefore, the phone-watch can only be used to check the time and make phone calls in class. (202104048-BEF-S)"

"I have my own mobile phone. After I finish my homework, I can use the phone to chat with my friends, or just play games for a while. (20210407-SY-S)"

However, it is necessary to have contact with the Internet and relating technology, since we cannot ignore the credit of information technology. Therefore, we need to help the parents have an open mind on the students' use of information technology.

\subsection{The Influence of the Number of Children at Home on Students' Information Literacy}

When the number of children in a student's family becomes larger, the information literacy score of this student decreases first, and then, increases. Specifically, the information literacy score of a student in a family with $1 / 2$ children is above 80 points, while that in a family with $3 / 4$ children is lower than 80 points. This is because the more children in a family, the less attention and educational resources they can obtain from their parents. Besides, a family with less children is more likely to be located in the urban area, and thus, the educational resources for the children in the family tend to be of high quality. It is worthwhile to mention that when the family have more 4 children, the score will exceed 80 points again. This is because there are more competitions among the children in order to get more attention from their parents.

\subsection{Students' Evaluation of Internet Learning}

On the whole, despite their limited access to the internet, the students have a clear understanding of online learning. Specifically, they can make full use of the advantages of online learning, while finding out some shortcomings. For example, one student utilizes online learning to preview polyphonic characters:

"If you have been in contact with mobile phones, such as looking up Chinese materials, you will be exposed to the polyphonic characters in the next lesson, and you will also be exposed to these mobile phones or computers. Occasionally, I think this way of learning is okay. (20210406-QLH-S\&T)"

Another student found that with the help of online learning, it is convenient to review the knowledge that they cannot follow in class, which enables personalized learning:

"Currently, I utilize a computer to assist learning. When I want to review certain knowledge, I can just print it out using my computer. (20210407-DJ-S1)"

At the same time, one student found out a shortcoming of online learning, i.e., lack of realistic interaction with teachers and lack of closeness.

"The school did not have online classes, but I am having online classes provided by XueErsi. Besides, I used to learn in Ape Guidance, Qingbei Online School, and ZuoYebang. The difference between online and offline classes is that in offline classes, I can feel a stronger sense of closeness, since teachers interact with us in reality while in online classed, we can only interact across the screen. Although the online class is very interesting, the sense of closeness is still not enough. (20210407-DJ-S3)" 
Some studies show that students who score as below proficient in information literacy (IL) skills have a miscalibrated self-view of their ability. Simply stated, these students tend to believe that they have above-average IL skills, when, in fact, an objective test of their ability indicates that they are below-proficient in terms of their actual skills. (Gross \& Latham,2012) While the majority of students think that their research skills are good or excellent, many of them are unable to conduct advanced information searches, judge the trustworthiness of health-related websites and articles, and differentiate between various information sources. (Ivanitskaya, O'Boyle, Casey, \& Ivanitskaya,2006) However, a research presented that the ILT scores provide reliable and valid measures of information literacy. (Katz,2007)

\subsection{Suggestions}

\subsubsection{Campus Network Communication Configuration Still Needs to Be Continuously Improved}

Although the teaching hardware has significantly improved in the rural area, the insufficient information transfer capability of school network still incurs unsatisfying performance for the interactive classes. Specifically, when the lecturers in the urban school tries to interact with the students in rural schools, it will take a long time before the students' response come back due to the severe delay of the school network, which incurs a slow pace for the class, and reduces the lecturer's enthusiasm to establish online interaction.

"The students in the city are on the scene, and the teacher can also call the students from the country school to answer simultaneously. However, synchronization is equivalent to simultaneous viewing, and the effect of the activity is very unsatisfactory, because the information transmission is stuck or delayed. The teacher here has spoken for a long time, and then the other side reacted. (20210407-SY-T1234)"

Unfortunately, it is challenging to overcome this problem, since it is hard to effectively reduce the network delay through device repair, and the cost for buying new device is unbearable at present.

Therefore, to provide an effective platform for resource sharing and knowledge creation, it is still necessary to strengthen the construction of network information technology in rural schools to ensure the immediacy of synchronized classrooms, which, however, remains a long way to go.

\subsubsection{Improve Urban-Rural Coordination Mechanism}

Synergy theory believes that the synergy effect of the system depends on the synergy between various subsystems within the system.(Jiong \& Liqin,2020) As far as the coverage area is concerned, the synchronized class is a collaborative development system of urban and rural education; as far as the teaching relationship in class is concerned, the synchronized class is a dual-teacher collaborative teaching system. This information and communication technology-based collaborative system is not based on close physical contact. The teachers of both parties involved in the teaching collaboration are likely to only "work together" temporarily through the virtual space of the network, which causes challenges to collaborative education between urban and rural schools, and it is imperative to build a stable and continuous urban-rural school coordination mechanism.

"The command of professional skills for teachers in urban and rural schools are similar, but the students in the city are accustomed to their unique way of learning. After all, the students in the city are different from those in the rural school. Therefore, it is difficult for teachers in urban schools to mobilize students. (20210409-HDW- T2)"

"Teachers in urban schools do not know the living habits of students in rural school, and what they teach is beyond the recognition of rural students, and the students don't understand it as a matter of fact. (20210408-WSY-T)"

There are differences between urban and rural students in terms of start point for learning and learning habits. Therefore, in the process of designing teaching plans, the lecturer needs to ensure that the teaching process can equally meet the learning needs of urban and rural students.

However, it is worth noting that even though the level of class participation is very limited, students in rural schools are still interested in synchronized classes. A rural school teacher thought that:

"We are in the countryside, and the students' vision is relatively limited, since they originally live in a relatively small region. But when they are having class together with urban children, they can learn from the urban children' new ideas which originates from the different environment they live in. (20210408-WSY-T)"

On the one hand, different knowledge backgrounds make it difficult for students to understand the content of the class; on the other hand, this out-of-the-ordinary learning experience provides them with opportunities to experience a wider world, which helps stimulating the students' interest in learning and exploration spirit. Therefore, it is necessary to establish an urban-rural coordination mechanism in the future.

\subsection{Deficiencies}

This research mainly investigates the application and understanding of students' information literacy, but does not 
investigate the ethics of students' information application. In the future, we can conduct further research on the ethics of students' information technology application in the western region. When some scholars study information literacy, they involve the moral cultivation of information literacy (Xiaomeng, Yan, \& Qiong,2007) and the dimension of information ethics (Wensheng,2006), which complement the related research on information ethics that people pay more attention to with the rapid development of information technology.

In addition, the sample size of rural students is small, which may lead to deviation of experimental results.

\section{Conclusion}

This study mainly evaluates the level and current situation of students' information literacy in the western region, and also analyzes and evaluates the differences in urban and rural education development and gender differences in information literacy application in the western region. Generally speaking, the information literacy level of primary school students in western China is at a medium level, but they have relatively few opportunities to get in touch with network information technology, mostly in information technology associations and courses. In addition, due to the gap between urban and rural resources and hardware equipment, urban students have a higher level of information literacy than rural students.

From the questionnaire data combined with the interview results, first of all, we look at the situation of school network access and home network access in general. Students score low on the situation of school network access, but in fact, they find that the situation of school network access is mostly good. Students may give low scores because the school restricts students' access to the Internet, so students cannot fully evaluate the situation of school network. Students' scores on home network are higher than those in schools, probably because students often check some study materials at home, and a few students use network equipment to chat or play games with their classmates at home, and they know more about the home network situation, but even so, parents also restrict students' behavior of touching the network.

Secondly, from the sub-dimension line chart, we can see that the score shows a downward trend, indicating that the higher the information literacy ability, the less the information technology behavior of students. This is due to restrictions on the use of electronic network equipment by families and schools. From the interview results, it can be seen that students have more behaviors at the lower level and less behaviors at the higher level.

From the scores and interviews, it can be seen that schools have strengthened their support for information technology courses in recent two or three years. However, with the increase of students' grades, information technology will be affected to some extent, because the curriculum pressure is also rising with the increase of grades.

Although it is found in interviews that a few families in rural areas still have the phenomenon of "preference for boys over girls", this has not affected the use of information technology. The concept of gender has basically changed in the western region, and there is no significant difference between genders in the use of information technology.

\section{Acknowledgement}

This paper is supported by National Natural Science Foundation of China (NSFC) under grant No.61977009. Thanks to the fund for its help.

\section{References}

ACRL. (2015). Framework for Information Literacy for Higher Education, 2015, from http://www.ala.org/arcl/standards/ils_recomm.pdf

Bent, M., Stubbings, R., \& Sconul (2011). The SCONUL Seven Pillars of Information Literacy: Core model

Chu, S. K. W., Tse, S. K., \& Chow, K. (2011). Using collaborative teaching and inquiry project-based learning to help primary school students develop information literacy and information skills. Library \& information science research, 33(2), 132-143. https://doi.org/10.1016/j.lisr.2010.07.017

Dan, G. (2009). We the Media 2. The Read-Write Web

Emmett, A., \& Emde, J. (2007). Assessing information literacy skills using the ACRL standards as a guide. Reference Services Review, 35(2), 210-229. https://doi.org/10.1108/00907320710749146

Foo, S., Majid, S., \& Chang, Y. K. (2017). Assessing Information Literacy Skills Among Young Information Age Students in Singapore. Aslib Journal of Information Management New Information Perspectives, 69(3), 335-353. https://doi.org/10.1108/AJIM-08-2016-0138

Gebhardt, Eveline, Friedman, Tim, Schulz, Wolfram,... Julian. (2014). Preparing for Life in a Digital Age. Amsterdam: IEA. (Reprinted).

Gross, M., \& Latham, D. (2012). What's Skill Got to Do With It?: Information Literacy Skills and Self-Views of Ability 
Among First-year College Students. Journal of the American Society for Information Science and Technology, 63(3), 574-583. https://doi.org/10.1002/asi.21681

Gut, D. M. (2011). Integrating 21st Century Skills into the Curriculum. In: Wan G., Gut D. (eds) Bringing Schools into the 21st Century. (https://doi.org/10.1007/978-94-007-0268-4_7ed., Vol.): Springer, Dordrecht. (Reprinted). https://doi.org/10.1007/978-94-007-0268-4_7

Hatlevik, O. E., Throndsen, I., Loi, M., \& Gudmundsdottir, G. B. (2018). Students' ICT self-efficacy and computer and information literacy: Determinants and relationships. Computers \& Education, 118, 107-119. https://doi.org/10.1016/j.compedu.2017.11.011

Huggins, A. C., Ritzhaupt, A. D., \& Dawson, K. (2014). Measuring Information and Communication Technology Literacy using a performance assessment: Validation of the Student Tool for Technology Literacy ((STL)-L-2). Computers \& Education, 77, 1-12. https://doi.org/10.1016/j.compedu.2014.04.005

Information Literacy Competency Standards for Higher Education - The Association of College and Research Libraries (ACRL). Information Literacy, 143-152

Ivanitskaya, L., O'Boyle, I., Casey, A. M., \& Ivanitskaya, L. (2006). Health information literacy and competencies of information age students: Results from the interactive online Research Readiness Self-Assessment (RRSA). Journal of medical Internet research, 8(2), e6. https://doi.org/10.2196/jmir.8.2.e6

Jiong, G., \& Liqin, Y. (2020). Synchronous classroom from the perspective of collaboration and interaction: essence, dilemma and solution path. Chinese Educational Technology, 09, 89-95.

Kang, M., Heo, H., Jo, I., Shin, J., \& Seo, J. (2010). Developing an Educational Performance Indicator for New Millennium Learners. Journal of Research on Technology in Education, 43(2), 157-170. https://doi.org/10.1080/15391523.2010.10782567

Katz, I. R. (2007). Testing information literacy in digital environments: ETS's Skills assessment. Information technology and libraries, 26(3), 3-12. https://doi.org/10.6017/ital.v26i3.3271

Mackey, T. P., \& Ho, J. (2005). Implementing a convergent model for information literacy: combining research and web literacy. Journal of Information Science, 31(6), 541-555. https://doi.org/10.1177/0165551505057018

Moeller, S., Joseph, A., Lau, J., \& Carbo, T. (2010). Towards Media and Information Literacy Indicators

O'Reilly, T. (2005). What is Web 2.0: Design Patterns and Business Models for the Next Generation of Software.

Panel, I. I. L. (2002). Digital Transformation: A Framework for ICT Literacy, 2002, from http: //www.ets.org/Media/ Research/pdf/ICTREPORT.pdf

Pinto, M. (2010). Design of the IL-HUMASS survey on information literacy in higher education: A self-assessment approach. JOURNAL OF INFORMATION SCIENCE, 36(1), 86-103. https://doi.org/10.1177/0165551509351198

Qingyu, R., \& Yi, B. (2013). "NAP-Information Literacy Evaluation System" in Australia (in Chinese). Chinese Information Technology Education, 007, 190-192.

Rosman, T., Mayer, A., \& Krampen, G. (2016). A longitudinal study on information-seeking knowledge in psychology undergraduates: Exploring the role of information literacy instruction and working memory capacity. Computers \& Education, 96, 94-108. https://doi.org/10.1016/j.compedu.2016.02.011

Schloman, B. F., \& Gedeon, J. A. (2016). TRAILS: Tool for Real-time Assessment of Information Literacy Skills. The Charleston Advisor, 17(3), 43-48. https://doi.org/10.5260/chara.17.3.43

Sha, Z., Yinghui, S., Longyan, J., \& Liqin, Y. (2018). Research on the Development and Application of Information Literacy Assessment Tool for Middle School Students (in Chinese). Chinese Audio-visual Education, 08(379), 78-85.

Vorobel, O., Voorhees, T. T., \& Gokcora, D. (2021). Language learners' digital literacies: Focus on students' information literacy and reading practices online. Journal of computer assisted learning. https://doi.org/10.1111/jcal.12550

Wang, L. (2007). Sociocultural Learning Theories and Information Literacy Teaching Activities in Higher Education. Reference and user services quarterly, 47(2), 149-158. https://doi.org/10.5860/rusq.47n2.149

Wen, J. R., \& Shih, W. L. (2008). Exploring the information literacy competence standards for elementary and high school teachers. COMPUTERS \& EDUCATION, 50(3), 787-806. https://doi.org/10.1016/j.compedu.2006.08.011

Wensheng, W. (2006). College students' information literacy and its cultivation (in Chinese). Research on audio-visual 
education, 10, 18-20.

Xiaomeng, W., Yan, W., \& Qiong, W. (2007). Investigation on Information Literacy of Teachers in Primary and Secondary Schools in Beijing (in Chinese). Chinese Audio-visual Education, 12, 24-29.

Yinghui, S., Changling, P., Di, W., \& Hao, Y. (2018). Study on the evaluation index system of information literacy of primary and secondary school students (in Chinese). Chinese Audio-visual Education, 08(379), 73-77.

\section{Copyrights}

Copyright for this article is retained by the author(s), with first publication rights granted to the journal.

This is an open-access article distributed under the terms and conditions of the Creative Commons Attribution license which permits unrestricted use, distribution, and reproduction in any medium, provided the original work is properly cited. 